\title{
Ventilation airflow around a continuous miner and its effect on methane concentrations at the face
}

\author{
Heather N. Dougherty
}

Follow this and additional works at: https://researchrepository.wvu.edu/etd

\section{Recommended Citation}

Dougherty, Heather N., "Ventilation airflow around a continuous miner and its effect on methane concentrations at the face" (2014). Graduate Theses, Dissertations, and Problem Reports. 5509. https://researchrepository.wvu.edu/etd/5509

This Thesis is protected by copyright and/or related rights. It has been brought to you by the The Research Repository @ WVU with permission from the rights-holder(s). You are free to use this Thesis in any way that is permitted by the copyright and related rights legislation that applies to your use. For other uses you must obtain permission from the rights-holder(s) directly, unless additional rights are indicated by a Creative Commons license in the record and/ or on the work itself. This Thesis has been accepted for inclusion in WVU Graduate Theses, Dissertations, and Problem Reports collection by an authorized administrator of The Research Repository @ WVU. For more information, please contact researchrepository@mail.wvu.edu. 


\title{
Ventilation airflow around a continuous miner and its effect on methane concentrations at the face
}

\author{
Heather N. Dougherty P.E., MBA \\ Thesis submitted \\ to the Benjamin M Statler College of Engineering and Mineral Resources \\ at West Virginia University
}

in partial fulfillment of the requirements for the degree of

Masters of Science in

Mining Engineering

Yi Luo, Ph.D., Chair

Felicia Peng Ph.D

Brijes Mishra Ph.D.

Department of Mining Engineering

Morgantown, West Virginia

2014

Keywords: Mining, Ventilation, Methane, Continuous Miner (CM), Anemometer Copyright (C) 2014 Heather Dougherty 


\title{
ABSTRACT
}

\section{Ventilation airflow around a continuous miner and its effect on methane concentrations at the face}

\author{
Heather N Dougherty
}

Attaining an accurate understanding of airflow distribution at the continuous miner face is instrumental in maintaining a safe mining environment. Currently, continuous miner face air readings can be taken in the last open crosscut and at the curtain mouth. By measuring airflow in a pre-determined area it is accepted that an adequate quantity of that air sweeps the face of harmful dust and gasses. Unfortunately, due to the location inaccessibility, precise face velocity readings can only be determined in a laboratory setting or through computer-simulated programs verified by laboratory models. The National Institute for Occupational Safety and Health (NIOSH) Office of Mine Safety and Health Research (OMSHR) ventilation gallery was used to simulate common ventilation scenarios and measure air velocities utilizing ultrasonic anemometers. The ventilation gallery simulates a full-scale mining face similar to a continuous miner (CM) room and pillar operation and provides a means to obtain representative air velocities in areas typically inaccessible on an actual CM face. Methane gas was also released from pipes located at the face to simulate realistic face gas emissions and dilutions.

Improving upon previous empty gallery testing and to more effectively determine representative face methane readings, a mockup of a continuous miner with water sprays and a scrubber fan was used to further refine face airflow conditions that would be closer to actual mining conditions. Throughout testing, methane was monitored along the face and at the machine-mounted monitor location allowing direct comparisons of concentrations at these critical locations. Multiple laboratory tests were run, varying parameters such as airflow quantity, entry width (sump or slab cut), and face ventilation configuration (blowing or exhausting curtain). Test data showed a similar pattern of methane concentrations at both low and high airflow quantities, but a difference in the distribution of methane concentrations between narrow and wide entry widths. As verified in previous research, most tests showed that blowing face ventilation was more efficient in diluting methane than exhausting ventilation. The patterns of airflow and methane concentrations observed in this testing can further improve the understanding of airflow in and around the CM and face, promoting effective use of face ventilation to improve the health and safety of miner. 


\section{Table of Contents}

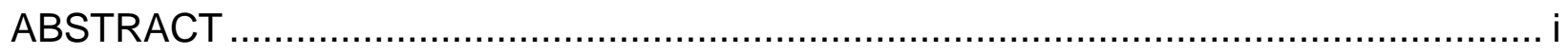

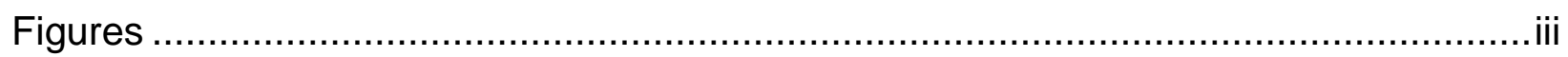

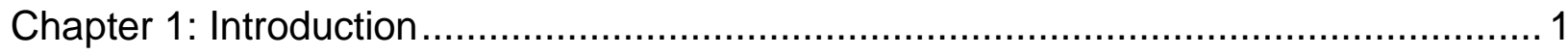

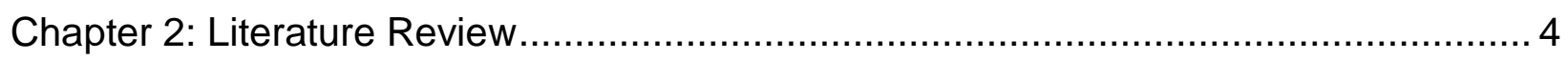

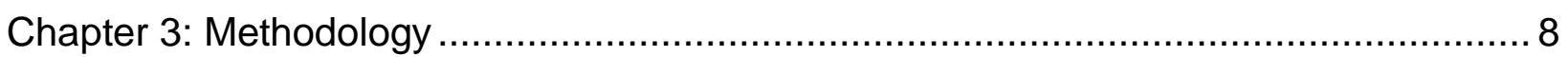

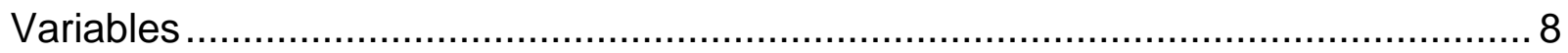

Ventilation Gallery - testing facility ….......................................................... 10

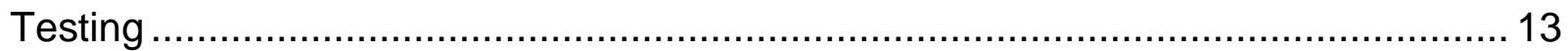

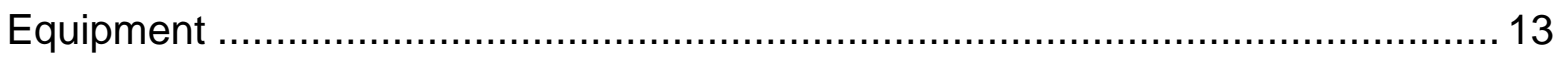

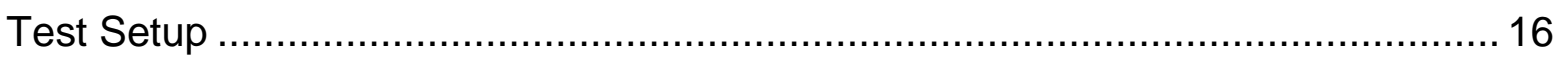

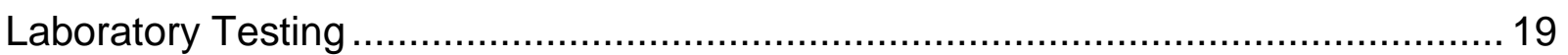

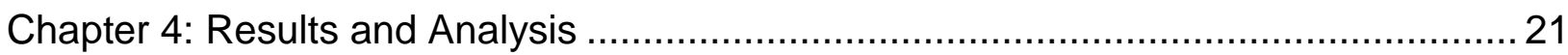

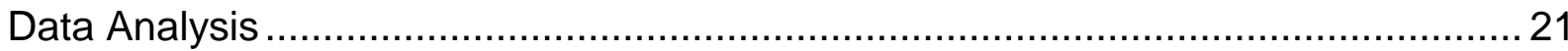

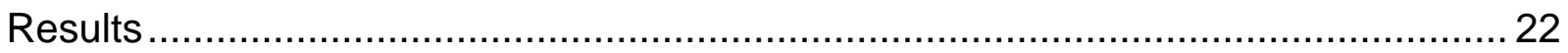

Detailed Analysis of Sump Cut, High flow scenarios........................................... 29

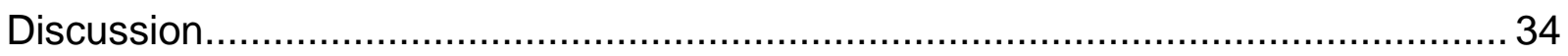

Chapter 5: Conclusions and Recommendations .................................................. 37

References:

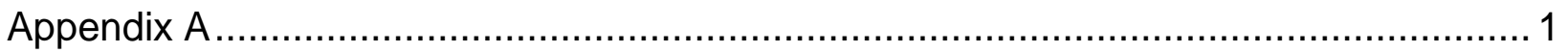




\section{Figures:}

Figure 1: Ventilation Test Gallery. (Taylor, Chilton et al. 2010) Arrows indicate air direction into the gallery in a blowing curtain configuration and out through an exhaust

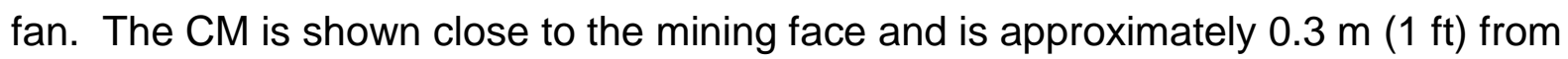

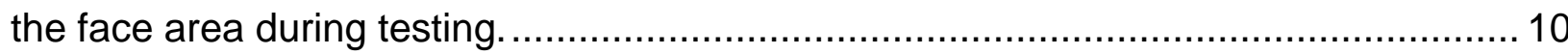

Figure 2: Model CM machine, top and side view.(Taylor, Chilton et al. 2010)............... 11

Figure 3 Water sprays on model mining machine. (Taylor, Chilton et al. 2010) ............ 12

Figure 4. Gas manifold at the test gallery face (Taylor, Chilton et al. 2010) ................. 13

Figure 5: The Gill 3-Axis Sonic Anemometer on a laboratory stand.......................... 14

Figure 6. Methane sampling system(Taylor, Chilton et al. 2010) .............................. 16 Figure 7 Support system for moving anemometer over top of miner.(Taylor, Timko et al. 2004)

Figure 8: Instrument placement within the test gallery. The small numbers represent methanometer locations and the large numbers represent anemometer locations. Narrow indicates Sump Cut, while Wide indicates slab cut. Scale is in feet................ 19 Figure 9: Ultrasonic anemometer senor heads with flow components (Taylor, Chilton et

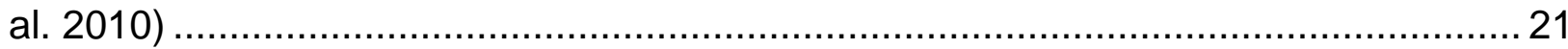

Figure 10. Reference angle directions in degrees.(Taylor, Timko et al. 2004) ............. 22 Figure 11: Graphical data of methane percentages for the sump and slab entry widths and showing blowing and exhausting ventilation for face methane monitoring Locations $1,2,3$, and 4 from Figure 8 . Sensor indicates the methane reading at the location of the machine-mounted methane monitor in the blowing or exhausting setup.

Figure 12: Velocity direction recorded in Degrees for Location 1 of the High flow, Sump Cut, Blowing Ventilation test case. Each series represents a test and the repeats .......32 Figure 13: A figure showing air velocity direction, the arrow indicates magnitude. NTS 34 


\section{Chapter 1: Introduction}

The technological advancements in continuous miner (CM) machines, particularly those with remote control equipment, make mining depths of greater than $6.1 \mathrm{~m}$ (20 feet) - deepcut mining, standard in underground coal mining. Deep cuts improve production rates but can also hinder fresh air from getting to the cutting face. It is important to understand the ventilation in and around the mining face so that preventative measures are taken to ensure air flow to the face for diluting the methane emitted during mining.

Methane, a naturally occurring coalbed gas is adsorbed into the solid coal matrix and exists in fractures in the coal or other surrounding rock is released during mining. When released from the coal during mining, if not properly diluted by ventilation air, methane in some zones can reach its explosive concentration to create a potentially hazardous environment.

However, the insufficient dilution problems could occur when coal mining operations are conducted with increased cutting depth, increased speed of mining cycles, and deeper mining depths. The foremost problem includes increased methane liberation within deeper coal beds and ventilation capacities being stretched to their limits. These complications can hinder getting adequate ventilation to the face for the dilution of methane gas.

All underground bituminous coal mines are considered gassy by the Mine Safety and Health Administration (MSHA) (CFR 2011) and have specific stipulations for minimal ventilation air required at the $\mathrm{CM}$ mining face. Historically, the designs and regulations for ventilating $\mathrm{CM}$ faces were developed for the standard maximum of a $6.1 \mathrm{~m}$ (20 foot) cut. MSHA has determined that $0.3 \mathrm{~m} / \mathrm{s}(60 \mathrm{ft} / \mathrm{min})$ of ventilation air is a basic minimum at the face where coal is being cut (CFR 2011) §75.326. As mines grow larger and increase cut area in the entry this can lead to a need for a greater volume of air to attain the required $0.3 \mathrm{~m} / \mathrm{s}(60 \mathrm{ft} / \mathrm{min})$ at the measurement point. With increased mining depths and mining speed, methane liberation is amplified and it consequently leads to the need to improve the ventilation air flow and efficiency. 
Ventilating the face to sweep away dangerous contaminants, such as methane, is crucial to the health and safety of mine workers. Title 30 Code of Federal Regulations (CFR 2011) part 75.342 stipulates that when the methane concentration reaches 1.0 percent, the monitor shall give a warning signal to a person who can de-energize the affected electric equipment or shut down the diesel-powered equipment. When the concentration at any methane monitor reaches 2.0 percent, the monitor "shall automatically de-energize the electric equipment or shut down the diesel-powered equipment on which it is mounted."(CFR §75.342(c)1 ) These regulations require methane monitors to be installed on all face machinery that cut or load coal, and to be placed "as close to the working face as practicable" (CFR §75.342(a)3). Because the machine-mounted methane monitor is not located on the face where methane concentration can be highest, its readings may not always reflect actual gas readings at the face. Since as early as the start of CM there have been concerns about the methane produced at the face exceeding the lower explosive limit (LEL) even when the average concentration was within standard limits (Kissell, Banfield Jr et al. 1974). Therefore, it is important to understand how airflow is coursed and how best to ventilate the deep cut face area for sweeping the contaminants away so that a safe operating condition is maintained.

A major problem associated with deep cut mining is the risk of methane explosions. An explosion in underground coal mine depends on three key elements in an underground coal environment, between 5-15\%methane concentration, oxygen, and an ignition source. Reducing or removing one of these basic elements is the key to reducing the likelihood of the explosion risk. Oxygen is a mandatory condition of human operation within the mining atmosphere, and therefore cannot be taken out of the matrix. Ignition sources such as the electrical power and the sparks created by metal cutting head striking hard material are also difficult to mitigate. Regular cutter bit changes and not allowing them to get dull has been found to reduce sparks (Colinet, Listak et al. 2010). Electrical power is standard in most mining equipment applications for cutting equipment, auxiliary ventilation, coal haulage devices, and belt conveyors. Although electrical standards are mandated to keep this equipment intrinsically safe in high risk areas. Methane, a byproduct of the mining process, can be diluted to non-explosive ranges using proper ventilation. Methane is the easiest source that can be monitored and manipulated to 
reduce the risk of explosions at the $\mathrm{CM}$ mining face and is controlled by the ventilation air. Ventilation is the most controllable component to create a safer environment for miners on the $\mathrm{CM}$ face. Ventilation has been studied in several ways to increase the safety of the face area for the deep cut. Understanding and controlling air at the CM face can assist in creating a safer and more productive mine.

The objective of this work is to further the understanding of airflow in the CM working face. The research is a continued effort beyond the airflow study in an unoccupied entry work done previously by $\mathrm{NIOSH}$. The experimental studies were conducted in a ventilation test gallery with a full-scale CM model placed in various possible locations. Blowing and exhausting curtain ventilations were provided to the gallery. The data generated from an intensive ventilation monitoring program enable the examination of both airflow and methane distributions at the face and around the CM. Airflow in the ventilation gallery was analyzed in different set up scenarios. The effectiveness of ventilation was determined by methane concentrations and airflow velocity. This information can be used to improve awareness of hazardous conditions at the CM mining faces, thus reducing the risk of methane ignition. 


\section{Chapter 2: Literature Review}

In early literature about ventilation in continuous miner places, it was initially determined that the percentage loss of air between the curtain and the face was often greater than that of the whole ventilation system (Stahl 1958, Schlick and Dalzell 1963). It was necessary to extend the line brattice as close to the mining face as possible to direct the air to the mining face to improve airflow to the face. Auxiliary ventilation using tubing and exhaust fans were later used to promote the air sweeping across the face. Schlick (1963) discussed using push and pull ventilation by the use of tubing and a machinemounted diffuser as auxiliary ventilation to assist in the air sweeping the face and diluting methane. CM sprays and scrubbers were not discussed, and the machine mounted diffuser appears to be the initialization of a scrubber system for the CM. Although at the time, it was stated that dust was a major issue with mining and ventilating the CM face (Stahl 1958, Schlick and Dalzell 1963).

There has been much research into ventilation on the CM face for dust, air flow and methane mitigation. Much of the work done in dust control concentrates on the innovations of machine mounted scrubbers, water sprays, and ventilation for reduction of respirable dust and concludes that the addition of these systems improves fresh air flow at the face (Volkwein and Thimons 1986, Taylor and Goodman 1997, Thimons, Taylor et al. 1999). It was found that the machine mounted scrubbers, used to reduce respirable dust by collecting dust from the air before it can reach the miner operator also assists in ventilating the face with increased brattice setbacks and assisted in diluting methane (Volkwein and Thimons 1986). Sprays are used to wet the coal for transportation to reduce dust and also assist in the airborne capture of dust at the cutting face (Kissell 2003). Dust control by spray has looked into the placement of these sprays on the $\mathrm{CM}$, and although there are some areas that are more effective at reducing dust, maintenance implications can determine where sprays will be more likely to function on a regular basis (Matta 1976). For example, sprays under the boom have been determined to be more effective, but because damage is more likely in this region, it is more commonly seen that the sprays are placed on the top of the boom. Type of water spray nozzle, water pressure, spray location and number of sprays are all 
characteristics of applications of sprays to reduce dust (Colinet, Listak et al. 2010). Various cone spray nozzles, pressures and water flow was compared to determine the air moving effectiveness of the parameters (Colinet, Listak et al. 2010). Taylor showed that the operation of water sprays does not significantly increase the volume of air reaching the face, but does direct the air across the face and improves mixing of the methane and the intake air at the face (Taylor, Chilton et al. 2010).

Additionally dust control parameters on $\mathrm{CM}$ faces include the operation of a machine mounted scrubber. Machine mounted scrubbers carry air from the face through ductwork within the miner and filter the air before it is released out of the back of the miner into the entry. Scrubbers, which when used effectively by approximately matching the scrubber flow with the intake flow can be an effective way to get intake air to the face and reduce methane concentrations. Although Taylor showed that regardless of the intake air flow, if the scrubber flow is increased the face methane will be reduced if recirculation is controlled by minimizing leakage around the curtain, and directing the scrubber exhaust away from the blowing curtain (Taylor, Chilton et al. 2010).

Taylor (2010) researched the effects of scrubber flow and water sprays on face ventilation flow, finding that scrubber use increased the amount of intake airflow reaching the mining face. They also examined the effect of curtain setback distance and its effect on face airflow and methane concentration. Proving that the closer the curtain is to the face, the better the dilution of methane, and quantity of air at the face. Previous ventilation gallery research has measured flow direction at various points within the empty entry to record ventilation velocity and direction (Taylor, Chilton et al. 2010). Methane concentrations were also logged and mapped, showing the influence of the ventilation on the methane concentrations in the empty entry.

Getting airflow to the face is of utmost importance to mine gassy coal quickly and successfully. Measuring of airflow accurately is important to achieving this aim for monitoring and altering of the airflow to the face to mitigate gas issues. Airflow has been measured in United States coal mines by the standard mechanical rotating vein anemometer using a zigzag transverse and is used as the standard airflow 
measurement equipment. Their use has been standard for over a century because of their ease of use, they give an on the spot reading of air flow, their small easy to transport size, and they can be used throughout the mine without the need for electricity. Some issues with the rotating vein anemometer is that the effects of dust can affect the performance as well as pulsing airflows and human error. Measurement of differential pressures is taken with a standard Pitot tube or manometer to calculate flow in tubes, regulators or fans. There have been many ways that engineers measure airflow in mines, some of the various ways include visible tracers including historically candles and smoke, chemical smoke tubes, gases tracers, streamers, Velometer, mechanical rotating vein anemometer, electrical sensing vein anemometers, vortex shedding flow sensors, pressure differential anemometers, hot wire anemometers, and ultrasonic are some devices that have been used (Unwin November 2007).

Other experimental ways to measure airflow on $\mathrm{CM}$ faces have been presented in research. Since measuring air flow and methane at the face is not possible in real mining situations because of roof control and safety issues, other methods have been developed to simulate this environment to better determine ventilation in this area. Full scale models of a CM face as in this research have been utilized experimentally to determine flow around the miner at the CM face, in the cut, methane and dust concentrations under controllable variables (Volkwein and Thimons 1986, Goodman and Taylor 1993, Thimons, Taylor et al. 1999, Taylor, Timko et al. 2004, Wala, Vytla et al. 2007, Taylor, Chilton et al. 2010). These full scale tests have also been integrated with other methods to cross verify methods primarily computational fluid dynamic and computer modeling. Other methods that have been used are scaled physical models and particle image velocimetry in laboratory setting also combined with full scale and computer modeling (Wala, Vytla et al. 2007).

Computational fluid dynamics (CFD) was utilized to model an empty entry (Wala, Vytla et al. 2007), validating NIOSH laboratory data. This was considered the first full scale CFD validation study. Air flow and methane concentration readings were not taken simultaneously due to safety concerns. It was proven, for these examples that with the validation information from the full scale test, CFD models were in good agreement 
(Wala, Vytla et al. 2007). Wala progressed to gathering methane data from the $\mathrm{NIOSH}$ test facility with the mock miner in place at the face and the scrubber on in various levels, comparing methane concentrations to CFD models(Wala, S et al. 2008). Hargreaves and Lowndes (2007) also utilized CFD to model face ventilation using tubing in a blowing face configuration. They showed ventilation patterns of airflow in various stages of cutting and bolting, finding CFD to be successful in identifying the ventilation characteristics associated with various auxiliary ventilation systems during a typical mining cycle. More recently Petrov, using CFD modeling, and small and large scale modeling developed a passive regulator that can assist in intake air penetration to the face (Petrov and Wala 2014). CFD is a powerful computer based tool that can predict detailed flow patterns to assist in the planning and variation of detailed ventilation at CM faces. Validation of these CFD models with full scale testing is imperative to good authentication of the CFD program. 


\section{Chapter 3: Methodology}

\section{Variables}

Two common practices of ventilating a $\mathrm{CM}$ face are blowing and exhausting ventilation. When implementing blowing ventilation the intake air is delivered to the face of the working $\mathrm{CM}$ entry by blowing it from behind a line brattice curtain or tubing. This intake air is blown at a higher velocity than the exhaust curtain due to the smaller area towards the face and sweeps away the face contaminants and is then exhausted in the entry towards the return. This system encourages the miner operator to be positioned behind the blowing curtain in the clean air while mining is taking place. Although this method is the most commonly used and most effective way of ventilating the face (Taylor, Chilton et al. 2010) it positions other mobile equipment operators like the shuttle car and roof bolters downwind of the $\mathrm{CM}$ in the return air. It also can restrict the movement, and possibly the visibility of the face to the continuous miner operator, due to the need to be in the fresh air while mining.

When implementing exhausting ventilation on the CM face, the intake air is delivered to the face from the working entry. The intake air sweeps the face, and the contaminant laden return air then is drawn behind the return curtain or through exhaust tubing to the return entries. This system allows all of the mobile equipment to be in the fresh air and allows the continuous miner operator to have more freedom of movement within the entry than with the blowing system. Both of the blowing and exhausting systems have various advantages and disadvantages and can be successfully implemented when a mining plan is determined and implemented.

Both water sprays on the CM machine and head and a scrubber fan system were used in this testing. These systems are a part of all CM mining best practices due to the fact that they minimize respirable dust and assist in diluting methane and directing ventilation air at the face area. CM machine sprays were consistent throughout experiments, with the flow and psi not varied with any testing, and just considered "on". Machine water sprays additionally act as a cooling and wetting agent which can reduce the potential for frictional ignitions. The machine scrubber flow was varied by orface 
plates on the front of the machine to reduce or increase flow to approximately match the flow of the intake air measured behind the curtain. Matching of these two values is considered a best practice due to the fact that it discourages recirculation of the return air to the face.

A common miner was used in this testing, which cuts a $5.0 \mathrm{~m}$ (16.5 ft) entry width in two cuts. This miner cuts initially a sump cut into the solid coal face, approximately $4.0 \mathrm{~m}$ $(13.0 \mathrm{ft}$ ) wide to a depth of approximately $12.2 \mathrm{~m}$ (40 feet). It then backs out of this position, re-positions to the "slab" of coal that is $1.0 \mathrm{~m}$ (3.5 feet) wide and cuts this Slab cut to make then entry approximately $5.0 \mathrm{~m}$ ( $16.5 \mathrm{feet})$ wide. Wider entries can be cut, full face miners are used, and wider entries are sometimes used in various mining configurations. The situation of a sump and slab cut with a maximum entry width of $5.0 \mathrm{~m}$ ( 16.5 feet) was chosen due to the limitations of the $\mathrm{NIOSH}$ ventilation gallery. Placement of the sonic airflow sensor placement in this study was limited by the current set up in the laboratory and equipment itself. These initial measurements, once studied with computer modeling will detail future locations for sensor placement in studies. Placement over top of the miner was identified as a prime location for information gathering of flow parameters in that area. Points behind the blowing or exhausting curtain were of importance as to monitor total flow that is getting to the CM face area. Locations behind the miner were meant to relay information on the airflow behind the miner in the entry.

Methane sensor placement was determined to be $0.3 \mathrm{~m}$ ( 1 foot) from the roof and $0.3 \mathrm{~m}$ ( 1 foot) from the face. This was decided because the methane is released from the face, and it is lighter than air, so a higher placement of sensors should gather information on the highest methane concentrations across the face. The division of the sensors along the face were due to other research placement of sensors, so that a comparison could be done (Taylor, Chilton et al. 2010) in the future if needed for calibration of computer modeling. The last methane sensor was placed in an area that would be similar to a machine mounted sensor placement on the mining equipment. This allowed comparison to what a miner would be reading on the equipment and what was actually being released from the mining face. 
Ventilation Gallery - testing facility

The ventilation test gallery is located at the NIOSH facility in Bruceton, PA, is an Lshaped building designed to mimic a CM face (Figure 1). The test gallery is a maximum of $2.1 \mathrm{~m}(7 \mathrm{ft})$ high and $5.0 \mathrm{~m} \mathrm{(16} \mathrm{1/2} \mathrm{ft)} \mathrm{wide.} \mathrm{Entry} \mathrm{width} \mathrm{can} \mathrm{be} \mathrm{varied} \mathrm{from} 4$ $\mathrm{m}$ to $5 \mathrm{~m}$ (ft) by moving walls made of curtain and wood. The ceiling and walls are covered in rough concrete material to simulate real world mine surfaces. The face of the test gallery is an airtight wall built across the entry with a gas manifold installed for uniform methane distribution (Figure 4).

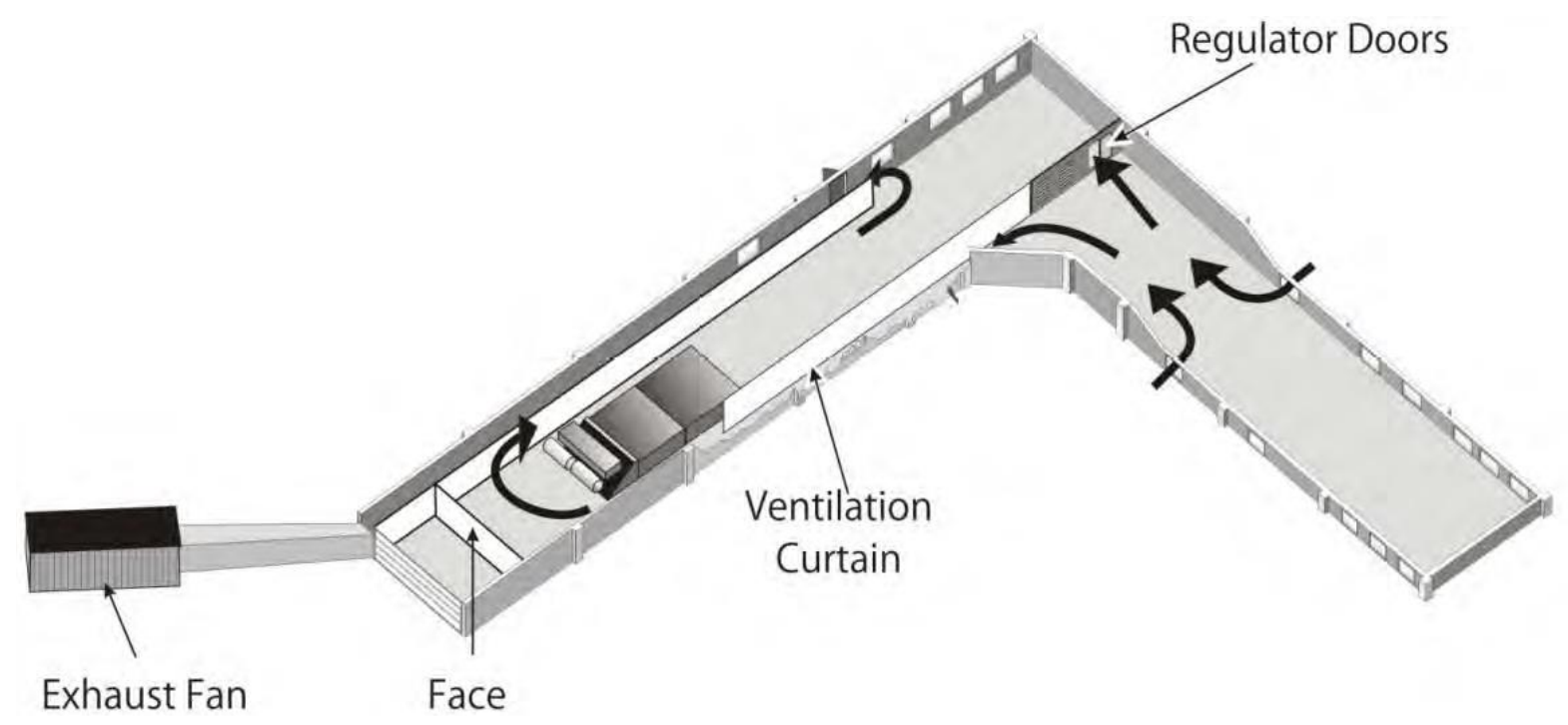

Figure 1: Ventilation Test Gallery. (Taylor, Chilton et al. 2010) Arrows indicate air direction into the gallery in a blowing curtain configuration and out through an exhaust

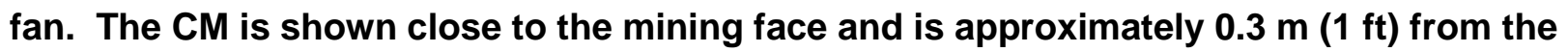
face area during testing.

A vane-axial exhaust fan located outside the test gallery has a flow capacity of $5.9 \mathrm{~m}^{3} / \mathrm{s}$ $\left(12,500 \mathrm{ft}^{3} / \mathrm{min}\right)$ and draws intake air through openings in the back of the test gallery. Tests can be conducted with either blowing or exhausting face ventilation by changing the curtain configuration within the laboratory. Airflow is varied by opening or closing regulator doors as shown in Figure 1. Curtain set back distance can be varied using wood frame and brattice removable walls. For this testing a curtain setback distance of 
35 feet was held constant throughout testing for both the blowing and exhausting set ups.

A full-scale model of a CM machine was used in the test gallery to simulate mining activity. The model is built of wood and covered with brattice curtain material (Figure 2) and is nearly the same outside dimension as a Joy $14 \mathrm{CM}$ without the rear loading boom.

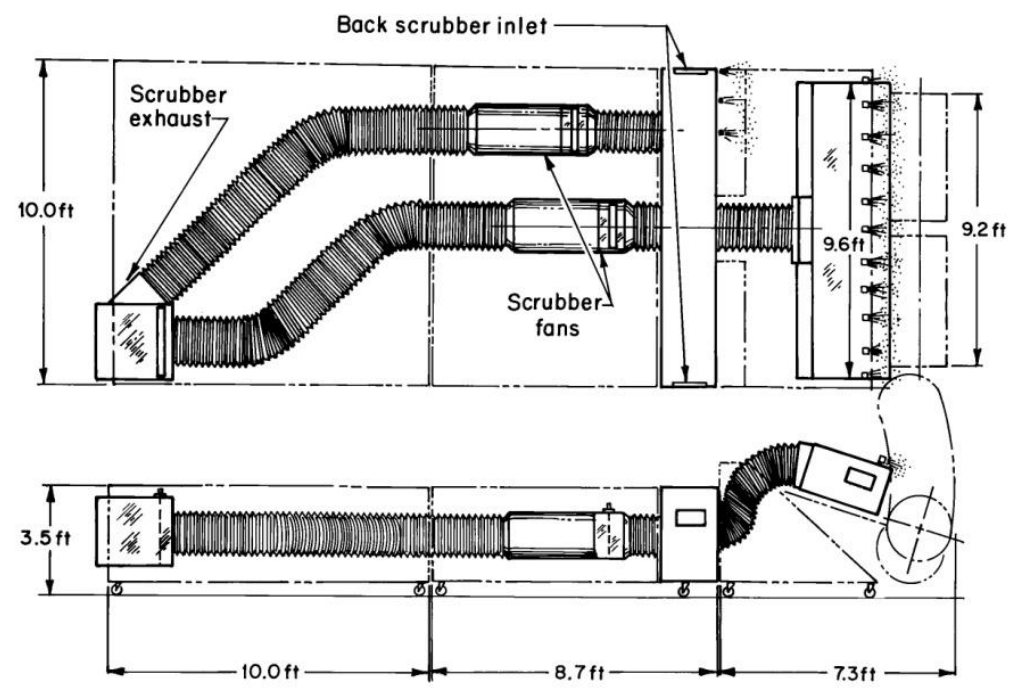

Figure 2: Model CM machine, top and side view.(Taylor, Chilton et al. 2010)

The CM machine is equipped with water sprays and incorporates a fan to simulate a dust scrubber. The vane axial scrubber fan produces airflow similar to that of an actual scrubber with a maximum capacity of $5.7 \mathrm{~m}^{3} / \mathrm{s}\left(12,000 \mathrm{ft}^{3} / \mathrm{min}\right)$. The scrubber fan draws air from two inlet openings on either side of the mining machine and one close to the front of the machine as seen in Figure 2 and exhausts through an outlet on the back right side of the machine. Orifice plates were installed in the scrubber ducting to adjust flow quantity to the approximate flow of the high and low flow rates. Two scrubber fans are installed within the miner with one as a backup with only one fan operating during testing. Scrubber velocity measurements were taken with a hot wire anemometer, and adjusted so that scrubber and intake quantity were approximately equal. Water spray manifolds were mounted on the top, sides, and under the boom of the mining machine, with the ability to utalize either straight or angled top sprays. Ten BD3 Spraying 
Systems, Co. hollow cone water spray nozzles were mounted on top of the miner using 3-m (10-ft) long plastic pipe operating at $0.48 \mathrm{MPa}$ (70 psi) water pressure and angled at approximately 30 degrees in the direction of the airflow sweeping the face from left to right.. In addition, four hollow cone nozzle sprays on each side of the CM spraying into the face were used spraying directly on the face to mimic mining situations. A schematic of the water spray set up is seen in Figure 3

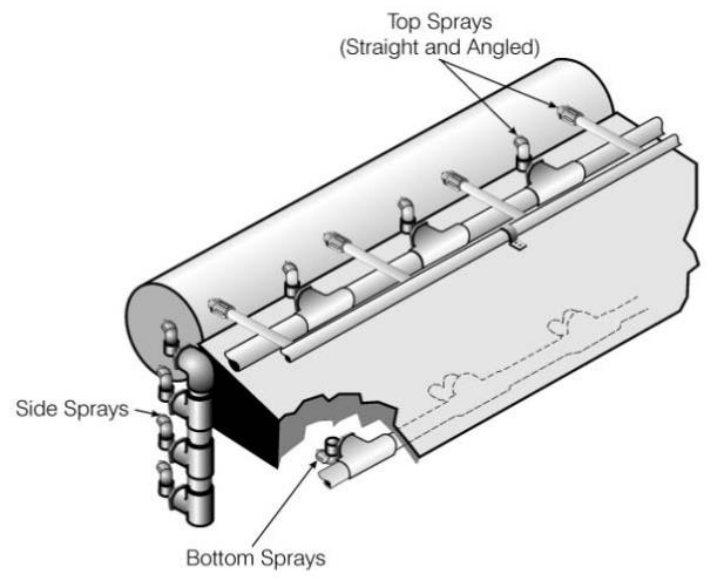

Figure 3 Water sprays on model mining machine. (Taylor, Chilton et al. 2010)

Figure 4 represents a uniform methane release from the test gallery face was simulated by a manifold system consisting of four horizontally positioned $3.8-\mathrm{cm}$ (1.5-inch) diameter copper pipes located $0.1 \mathrm{~m}$ (4 inches) away from the face. The four pipes were equally spaced in the $2.1-\mathrm{m}$ (7-ft) high face area and were perforated on the top and bottom with 2-mm (1/16-in) diameter holes placed $50 \mathrm{~mm}$ (2 in) apart. Original length of the pipes for the $4.0 \mathrm{~m}$ (13 ft) face is $3.0 \mathrm{~m}$ (10 feet). Extension pipes were added when the face width changed from $4.0 \mathrm{~m}$ to $5.0 \mathrm{~m}$ (13 ft to $16.5 \mathrm{ft}$ ) during the slab cut extending the pipes to approximately $3.6 \mathrm{~m}$ (12 feet). Gas flow rates were set using a flow meter and could be varied from 3.8 to $16.5 \times 10^{-3} \mathrm{~m}^{3} / \mathrm{s}$ (8 to $35 \mathrm{cfm}$ ). A methane flow of $8.5 \times 10^{-3} \mathrm{~m}^{3} / \mathrm{s}(18 \mathrm{cfm})$ was maintained during testing to keep the methane levels in the ventilation gallery below two percent due to safety concerns. A commercial natural gas source of approximately 99 percent methane was used for testing. 


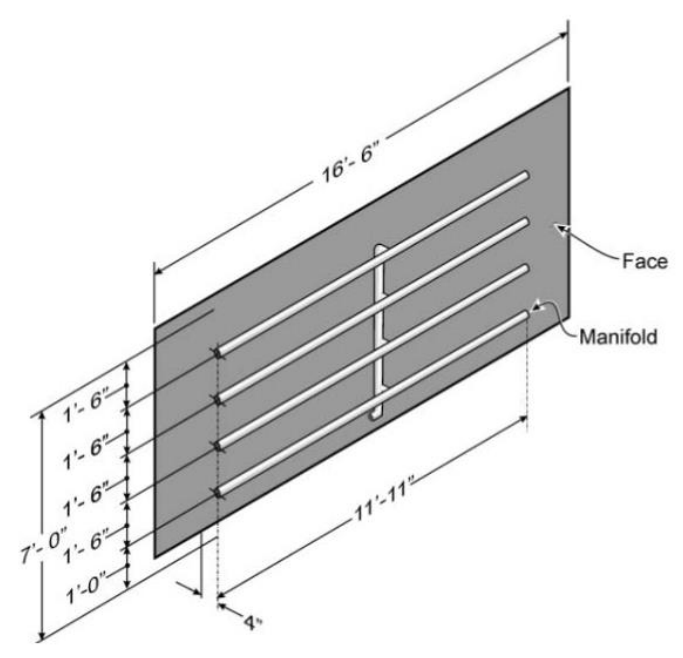

Figure 4. Gas manifold at the test gallery face (Taylor, Chilton et al. 2010)

Redundant safety precautions are taken within the ventilation gallery due to the use of methane in testing. All work is planned with the maximum methane in any monitored location to be $2.0 \%$ or less. Gallery safeguards include an automatic gas shut off if the main gallery fan is not in operation, strobe lights on the gallery to alert others in the area that methane is being used within the laboratory, and an automatic shut off if there is power on within the gallery. All power must be off when methane is being used in the gallery. Due to this safeguard, ventilation air flow and methane were monitored separately.

Testing

Equipment

Ultrasonic anemometers as shown in Figure 5 are designed for measuring velocity in a two- or three-dimensional space. These anemometers are robust, are easily adaptable to changing environments, and are used extensively in meteorological applications. Gill ultrasonic anemometers were used for acquiring air velocities in the ventilation test gallery. These anemometers have been successful in laboratory testing due to their ease of use and lack of required calibration when moved to different locations (Martikainen, Dougherty et al. 2010, Martikainen, Taylor et al. 2011). The measurement of air velocity vectors is based on the speed of the sound pressure wave and distance 
between the sensor heads. The ultrasonic anemometers chosen were Gill Windmaster (2011) instruments, which measure air velocity and direction in all three axes. The instrument has a velocity range of $0-45 \mathrm{~m} / \mathrm{s}(0-8,900 \mathrm{fpm})$ with a resolution of $0.01 \mathrm{~m} / \mathrm{s}$ $(2.0 \mathrm{fpm})$ and a direction range of $0-359^{\circ}$ with a resolution of $0.1^{\circ}$. They are powered by a 12-volt power source and data is recorded from the instrument through a cable to a power communications box by a RS232 connection. This box is then connected via an Ethernet cable to an Ethernet hub, for use with multiple instruments, and finally to the laboratory computer data acquisition system.

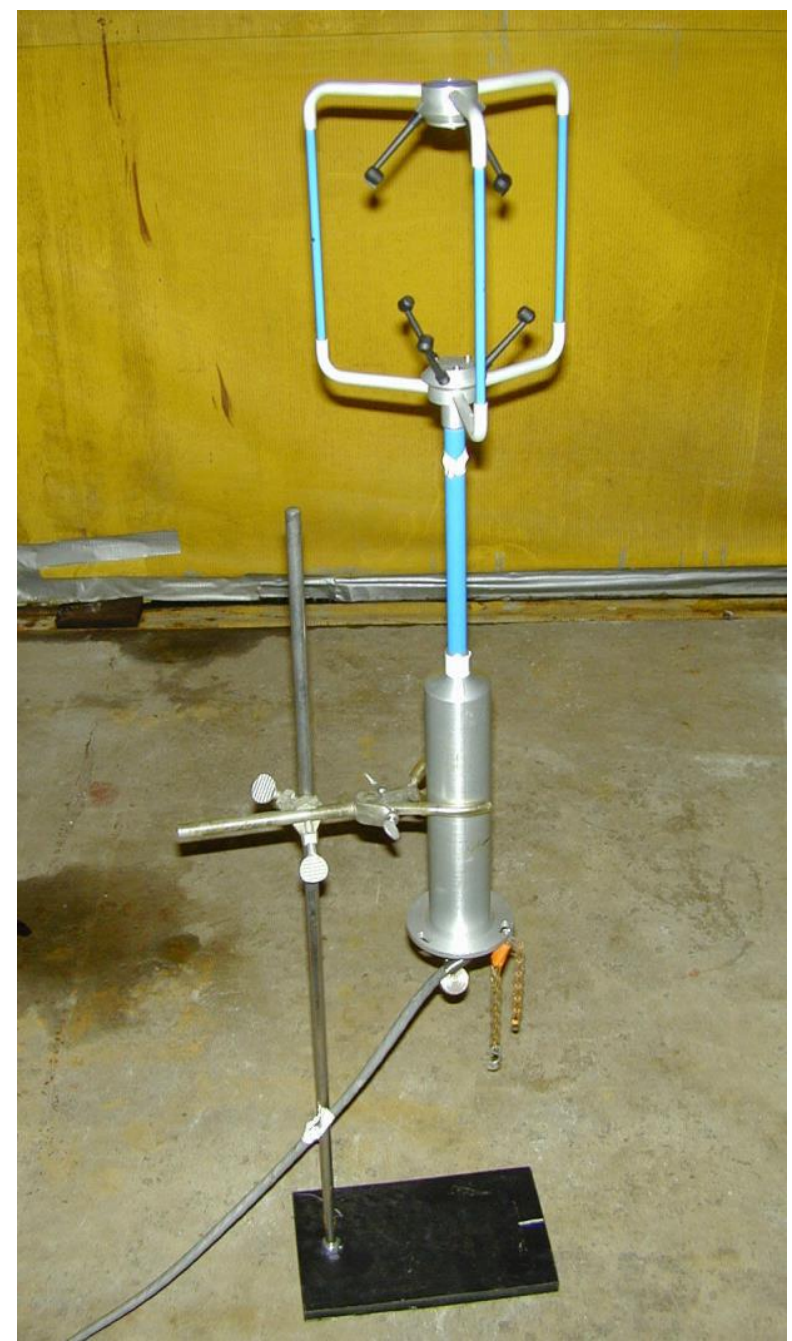

Figure 5: The Gill 3-Axis Sonic Anemometer on a laboratory stand.

Procedures were developed for use of these ultrasonic instruments for measuring both airflow direction and velocity in the ventilation test gallery (Taylor, Chilton et al. 2002, Taylor, Chilton et al. 2002, Taylor, Timko et al. 2004, Hall, Taylor et al. 2007, Taylor, 
Timko et al. 2007, Taylor, Chilton et al. 2010). Each instrument was manually placed in test locations as indicated by the large numbers in Figure 8. A total of four 3-axis Gill Windmaster ultrasonic anemometers were used during testing and were moved to multiple locations within the laboratory to measure additional test locations.

Methane concentrations can be monitored simultaneously at up to 16 locations in the ventilation test gallery. For these tests, only 5-6 methane sampling locations were chosen dependent on the width of the face. These testing locations were chosen to allow for close examination of maximum methane concentration areas in relation to air velocity sensor readings. Plastic tubing was connected to a vacuum pump, which draws air samples from each sampling location within the test gallery to an individual Bacharach CE130 combustible gas detection transmitter located outside of the test gallery. Each air sampling tube is the same length with an metal end piece on the tube on the laboratory end to discourage water from being gathered in the lines and progressing to the methane sensors as seen in Figure 6. Water separators are also located outside of the laboratory, connected prior to the sensors, to further verify that water does not reach the methane sensors. Methane sensors were calibrated weekly unless a discrepancy was found between multiple runs of the same test parameters. 


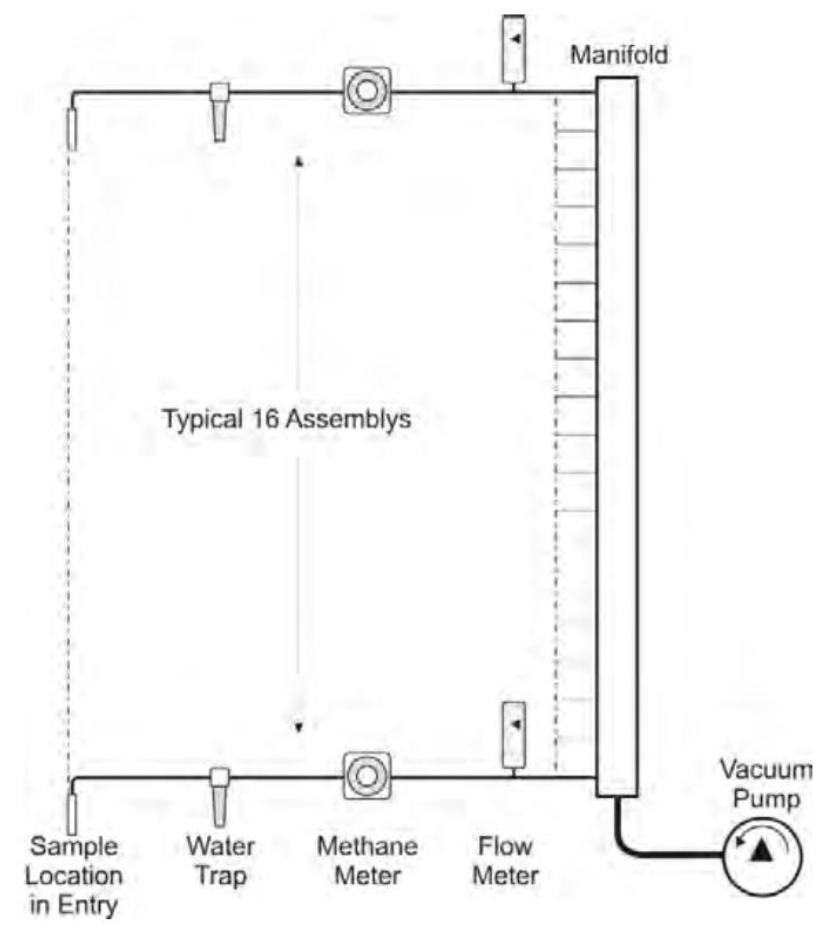

Figure 6. Methane sampling system(Taylor, Chilton et al. 2010)

A LabVIEW (2012) data acquisition program was created, called Mine Ventilation Acquisition System (MVAS), to simplify test data collection from anemometer and methanometer locations within the laboratory. Information that was inputted and saved in MVAS was location in the $X, Y$, and $Z$ plane of each of the air velocity sensors and methane monitors, water pressure, intake velocity, scrubber velocity, and curtain location and configuration. Test time, airflow velocities, water pressures, and methane concentrations were collected; data was stored and transferred to a Microsoft Excel file for processing and analysis.

\section{Test Setup}

Testing criteria chosen and factors that were varied were curtain location, intake air and scrubber flow rates, and entry cut (or width). Intake flow rate at a high flow rate of approximately $4.7 \mathrm{~m}^{3} / \mathrm{s}(10,000 \mathrm{cfm})$ was chosen, the range that was read by the instruments was between $3.8 \mathrm{~m}^{3} / \mathrm{s}$ to $5.3 \mathrm{~m}^{3} / \mathrm{s}(10,500-14,700 \mathrm{cfm})$. The low flow setting of $2.0 \mathrm{~m}^{3} / \mathrm{s}(6,000 \mathrm{cfm})$ was chosen, and was recorded at a range of $2.3 \mathrm{~m}^{3} / \mathrm{s}$ to $3.5 \mathrm{~m}^{3} / \mathrm{s}(6,300-9,600 \mathrm{cfm})$ by the instruments. The airflow data shows more variation 
than was actually encountered during testing because the recording instrument takes a point reading rather than a full-entry cross section reading. The anemometer that was placed behind the curtain was placed at a centerline, which is known to have the highest ventilation velocity due to less friction from the ribs being at the furthest point away from them. An additional variation in intake air quantities occurred because initial airflow settings were made before the scrubber fan on the $\mathrm{CM}$ was turned on. Face

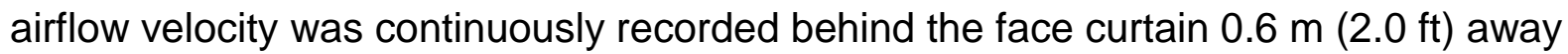
from either the left or right rib. The face curtain was placed on the left side of the entry for blowing face ventilation or on the right side for exhausting face ventilation. A two-

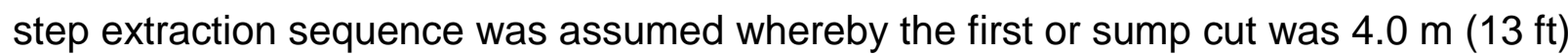
wide, followed by removal of the slab to make the final entry width of $5.0 \mathrm{~m}(16.5 \mathrm{ft})$. For all tests, curtain setback distance was $10.7 \mathrm{~m}$ (35 ft), water spray pressure was 70 psi, water sprays on the top of the boom were angled approximately $30^{\circ}$ pointing to the right side of the face, and the dust scrubber was "on." Scrubber flow was adjusted to be approximately equal to the intake airflow quantity. A test matrix of the six variables is shown in Table 1. The eight tests were run and repeated twice, for a total of three test duplications of each setup. One set of test iteration data was corrupted within the file and could not be processed, the two iterations of this test were analyzed.

Table 1: Test matrix for gallery testing

\begin{tabular}{|l|l|l|l|l|l|l|l|l|}
\hline \multicolumn{1}{|c|}{ Test \# } & $\mathbf{1}$ & $\mathbf{2}$ & $\mathbf{3}$ & $\mathbf{4}$ & $\mathbf{5}$ & $\mathbf{6}$ & $\mathbf{7}$ & $\mathbf{8}$ \\
\hline Airflow Quantity & & & & & & & & \\
\hline High (4.7 m3/s) & $\mathrm{X}$ & $\mathrm{X}$ & $\mathrm{X}$ & $\mathrm{X}$ & & & & \\
\hline Low $(2.0 \mathrm{~m} 3 / \mathrm{s})$ & & & & & $\mathrm{X}$ & $\mathrm{X}$ & $\mathrm{X}$ & $\mathrm{X}$ \\
\hline Ventilation Setup & & & & & & & & \\
\hline Exhausting face curtain & $\mathrm{X}$ & $\mathrm{X}$ & & & $\mathrm{X}$ & $\mathrm{X}$ & & \\
\hline Blowing face curtain & & & $\mathrm{X}$ & $\mathrm{X}$ & & & $\mathrm{X}$ & $\mathrm{X}$ \\
\hline Entry Width & & & & & & & & \\
\hline Second/slab cut & $\mathrm{X}$ & & $\mathrm{X}$ & & $\mathrm{X}$ & & $\mathrm{X}$ & \\
\hline First/sump cut & & $\mathrm{X}$ & & $\mathrm{X}$ & & $\mathrm{X}$ & & $\mathrm{X}$ \\
\hline
\end{tabular}


Four ultrasonic anemometers were used for testing as seen in Figure 9. Ten to eleven air flow test locations were used depending upon the entry width as shown in Figure 8. Each setup was run multiple times due to the limited number of instruments, with the anemometers moved to different locations to complete each test. Two units were placed above the CM machine and located $0.8 \mathrm{~m}(2.5 \mathrm{ft})$ below the roof and $0.9 \mathrm{~m} \mathrm{(3}$ feet) from each edge of the CM with $1.2 \mathrm{~m}$ (4 feet) between each as seen in Figure 8. The anemometers were then moved to locations $3.7 \mathrm{~m}$ (12 feet), $6.1 \mathrm{~m}$ (20 feet), and $8.5 \mathrm{~m}$ (28 feet) back from the mining face. The anemometer locations above the min miner were mounted upside-down to a garage door frame and moved along the installed tracks as seen in Figure 7. The CM location is indicated by the shaded area in Figure 8. The 3.7-m (12-ft) distance from the face was chosen as the closest point so that the water sprays would not directly affect the readings of the ultrasonic anemometers (Taylor et al., 2010). Another ultrasonic anemometer was placed behind

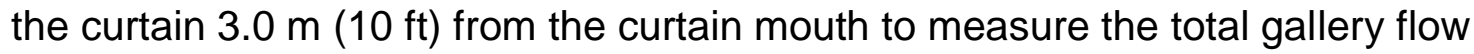
(Location 11 in the exhausting, and Location 7 in the blowing setup in Figure 8). This anemometer was stationary throughout testing, placed on a stand $1.1 \mathrm{~m}(3.5 \mathrm{ft})$ from the floor, and $0.3 \mathrm{~m}(1 \mathrm{ft})$ from the rib. The fourth anemometer was placed on a stand in

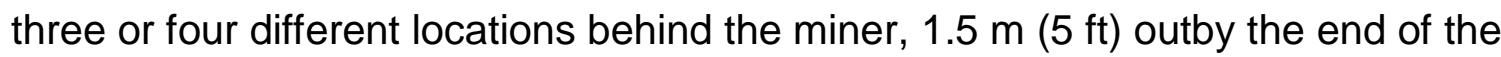
curtain and $1.1 \mathrm{~m}(3.5 \mathrm{ft}$ ) high (Locations 7-10 or 8-11 in Figure 8).

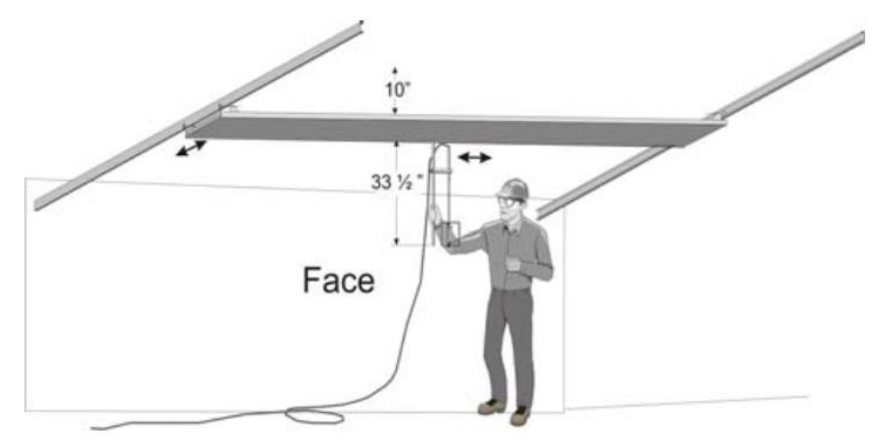

Figure 7 Support system for moving anemometer over top of miner.(Taylor, Timko et al. 2004) 


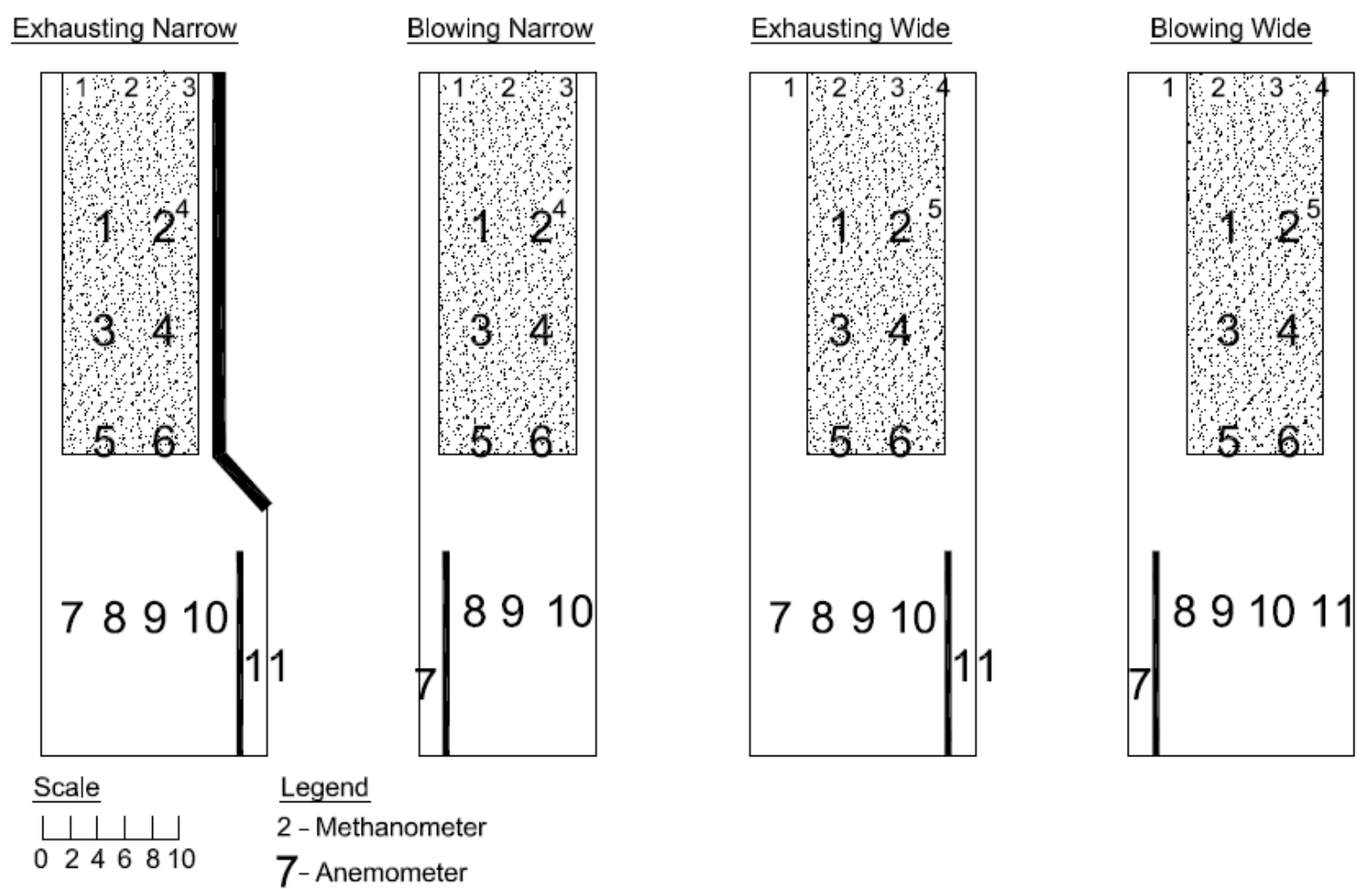

Figure 8: Instrument placement within the test gallery. The small numbers represent methanometer locations and the large numbers represent anemometer locations. Narrow indicates Sump Cut, while Wide indicates slab cut. Scale is in feet.

Methane sampling tubes were placed $0.3 \mathrm{~m}(1 \mathrm{ft})$ from the roof and $0.3 \mathrm{~m}(1 \mathrm{ft})$ from the face. For blowing or exhausting face ventilation with the sump cut entry, three sampling tubes were placed along the face and another at the standard machine-mounted methanometer location on the $\mathrm{CM}$, located $2 \mathrm{~m}(7 \mathrm{ft})$ from the face and $1 \mathrm{~m}(3 \mathrm{ft})$ from the roof on the right side of the machine (Location 4 in the slab cut; Location 5 in the sump cut in Figure 8). For the slab cut scenarios, a fourth methane collection tube was added at the face.

\section{Laboratory Testing}

Test airflow measurements were recorded for approximately three minutes at a sample rate of once per second. After moving the anemometers, airflow was stabilized and the data recording was re-started. Ventilation data was recorded in vectors, with 
components in the horizontal plane used to calculate flow and direction. Although the three-axis instrument also measures flow in the vertical direction, velocities were only calculated in the horizontal plane. All anemometers were situated with the North arrow pointing towards the face. Figure 10 shows the reference directions in degrees referencing the face.

A constant methane flow of approximately $18 \mathrm{cfm}$ was maintained by monitoring a flowmeter and rotometer. To ensure thorough mixing, methane was released into the gallery for approximately five minutes to establish steady-state conditions before recording methane readings once per second for approximately 10 minutes. Once recording of methane data was complete, the methane was turned off, and we allowed the methane to be eliminated from the laboratory by monitoring the sensors before we re-entered and turned electrical power on.

Both ventilation and methane data from each test was compiled into one excel file. Histograms were compiled and were used to determine that the data was valid, and the mean, median, and mode were found (See Appendix A for all Statistical calculations, histograms and graphs for all locations for Blowing ventilation, High flow, Sump Cut). Maximums and minimums were also noted and analyzed. 


\section{Chapter 4: Results and Analysis}

\section{Data Analysis}

Air flow data was recorded for an approximately three minute sampling period, recording one value per second (180 data points) as determined in testing protocol for ultrasonic laboratory testing (Taylor, Timko et al. 2004). This data was recorded in three directional vector components $(\mathrm{U}, \mathrm{V}$ and $\mathrm{W})$. These three components are orthogonal and correspond to flow in what we would refer to the $\mathrm{X}, \mathrm{Y}$, and $\mathrm{Z}$ directions (Figure 9: Ultrasonic anemometer senor heads with flow componentsFigure 9).

The U, or $\mathrm{X}$ ( 0 to 180 ) direction corresponding to flow toward and away from the face, to the right and left across the entry recorded in the $V$ or $Y$ (90 to 270) as in Figure 10 direction, and up and down referring to the $W$ or $Z$ direction (Taylor, Timko et al. 2004). UVW mode was used on the ultrasonic anemometers and data was recorded in vector form for UVW directions if available. The data was then transferred to an excel spreadsheet where the data was calculated to determine flow magnitude and direction at each point in Figure 8 in the $X$ and $Y(U V)$ directions. The mean of this data was taken for each test iteration and was then averaged with the reiterations of the tests. Histograms and statistical analysis of the data was created to determine if the velocity data was statistically normal, please see Appendix A for the detailed analysis of one of the tests.

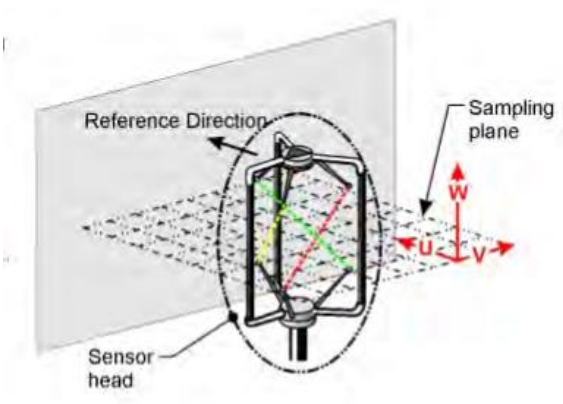

Three Axis

Figure 9: Ultrasonic anemometer senor heads with flow components (Taylor, Chilton et al. 2010) 
Methane data was recorded in all of the locations in the same test. Methane samples were taken once per second, but the test was run for approximately 10 minutes (approximately 600 sample readings).

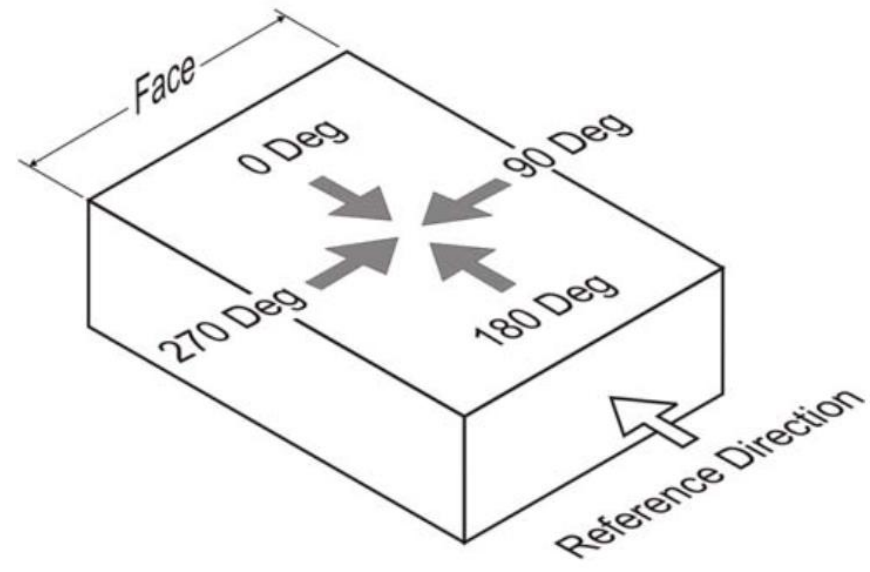

Figure 10. Reference angle directions in degrees.(Taylor, Timko et al. 2004) Results

Methane data was analyzed to determine which ventilation setup has the most efficient face airflow configuration. The minimum methane concentration at any location when compared to the other setups determined the best scenario, giving an indication of airflow effectiveness close to the face. Distribution of the methane along the face also allows estimation of airflows close to the face, identifying areas of lower flow by presenting higher concentrations of Ch4. Figure 11 shows methane data as recorded for all test locations and compares blowing to exhausting ventilation. In Figure 11, the dotted line indicates the reading at the $\mathrm{CM}$ machine sensor location for the exhausting ventilation case, and the solid line indicates the sensor location reading for the blowing ventilation case. 

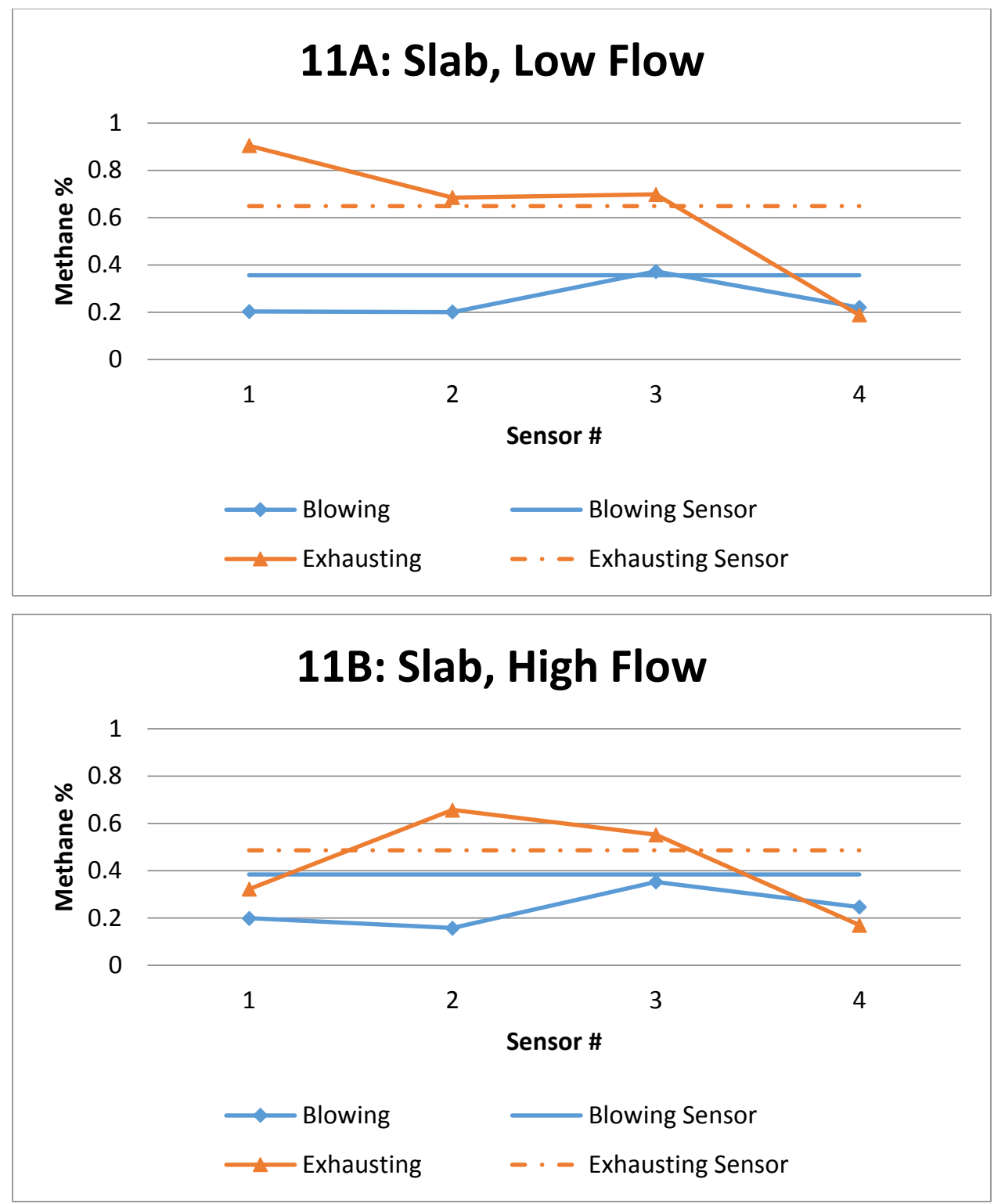

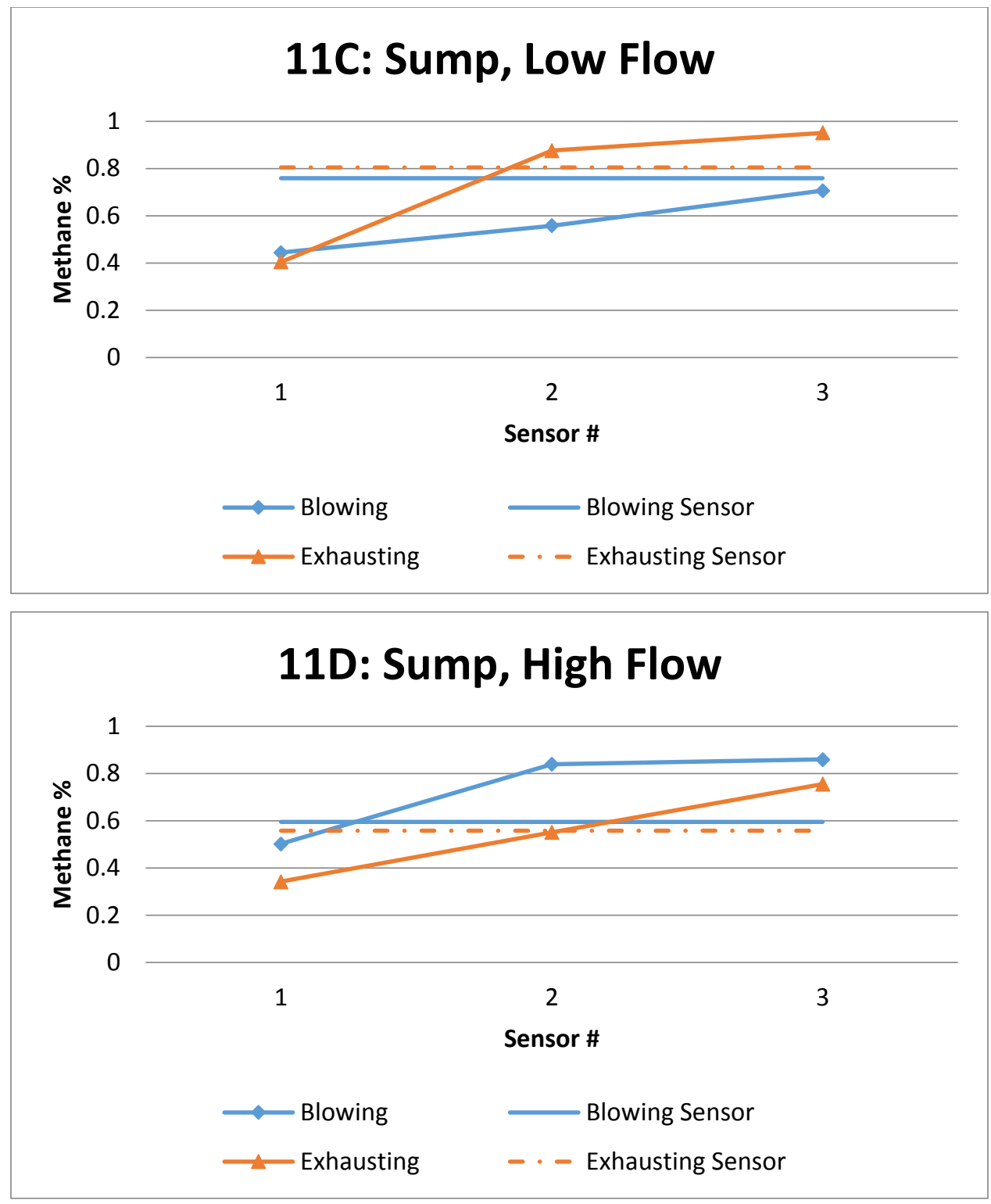

Figure 11: Graphical data of methane percentages for the sump and slab entry widths and showing blowing and exhausting ventilation for face methane monitoring Locations $1,2,3$, and 4 from Figure 8 . Sensor indicates the methane reading at the location of the machine-mounted methane monitor in the blowing or exhausting setup.

Methane concentration data for the sump cut in Figure 11C and Figure 11D show that the highest concentration was recorded in the right corner of the face (Location 3 from Figure 8) while Figure 11A and Figure 11B show that for the slab cut this corner showed a much lower face methane reading (Location 4 from Figure 8) when compared to other readings across the face. A possible cause is ventilation air flowing strongly 
with a higher velocity from left to right in the sump cut, contributing to the higher methane concentration on the right side, similar to an empty entry observed by Taylor(Taylor, Chilton et al. 2010). In the wider entry or slab cut, this same pattern was not consistent. The slab cut consistently has higher methane concentrations than the sump cut, most likely due to the larger area of the cut.

Table 2 compiles velocity data for all locations from Figure 8, showing in all cases that the left side location closest to the face (Location 1) has a higher velocity than the right side (Location 2). Kissell (1979) demonstrated that water sprays act as small airmoving fans, directing air across the face from left to right; therefore this type of result would be expected. In most other locations above the mining machine, velocity was higher on the left-hand side during both blowing and exhausting ventilation scenarios. This could be due to the scrubber system taking a portion of the intake air from the face before it completes a sweep across the face or because the anemometer locations were outby the scrubber inlets. The blowing ventilation, sump cut case in both high and low flow were the only scenarios that showed a difference in the two locations above the

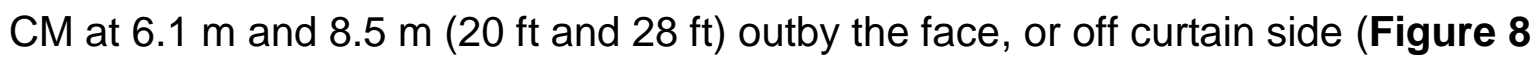
Locations 3-4 and 5-6). Each showed a higher velocity on the right-hand side than on the left side, but still with a higher velocity $3.7 \mathrm{~m}(12 \mathrm{ft})$ from the face on the left-hand side or curtain side (Location 1 from Figure 8).

All intake air within the system was assumed to have flowed into the scrubber system and exhausted out of the back of the CM machine. In all blowing and exhausting cases, locations behind the miner (Figure 8 Locations 7-10 or 8-11) showed ventilation air flowing towards the face, most likely due to these locations being only $1.5 \mathrm{~m}(5.0 \mathrm{ft})$ outby the end of the curtain. Anemometer placement did not detect the scrubber exhaust, directed outby or away from the mining machine mainly due to the fact that the anemometer reading location was above the scrubber exhaust.

Air velocity direction was computed for all points and all tests, but was not analyzed with the methane and velocity data. In the detail analysis section of this Thesis information for one of the tests is discussed for all components, methane, velocity and air direction. With additional information for this test in Appendix A. 
Table 2 shows that in most cases exhausting ventilation has a higher mean velocity airflow than blowing in recorded location, but does not necessarily indicate that it is more effective at ventilating the $\mathrm{CM}$ face. Methane readings in Figure 11 prove this otherwise. Various reasons why the flow is higher could be that the velocity of the air behind the curtain varies and at times the exhausting curtain had higher mean velocities, which can lead to higher velocities at points within the laboratory. Additionally the points chosen to record velocity readings may not be able to acquire some of the flows accurately around the miner. The current data should be used to validate a CFD model which can then lead us to establishing better locations for recording ventilation readings, permitting us a better understanding of airflow around the $\mathrm{CM}$ miner and face.

Table 2: Mean ventilation velocity at locations in meters per second from locations in Figure 8. Highlighted velocities are behind the curtain values.

\begin{tabular}{|c|c|c|c|c|c|c|c|c|c|c|c|c|c|}
\hline \multirow{2}{*}{$\begin{array}{l}\text { Entry } \\
\text { Width }\end{array}$} & \multirow{2}{*}{$\begin{array}{c}\text { Ventilation } \\
\text { Setup }\end{array}$} & \multirow[b]{2}{*}{ Flow } & \multicolumn{11}{|c|}{ Location } \\
\hline & & & 1 & 2 & 3 & 4 & 5 & 6 & 7 & 8 & 9 & 10 & 11 \\
\hline \multirow{4}{*}{$\begin{array}{l}\text { Slab } \\
\text { Cut }\end{array}$} & \multirow[t]{2}{*}{ Blowing } & Low & 0.49 & 0.21 & 0.46 & 0.35 & 0.48 & 0.48 & 2.46 & 0.29 & 0.39 & 0.39 & 0.70 \\
\hline & & High & 0.87 & 0.30 & 0.78 & 0.73 & 0.94 & 0.76 & 3.81 & 1.79 & 2.36 & 2.05 & 1.48 \\
\hline & \multirow[t]{2}{*}{ Exhausting } & Low & 0.90 & 0.54 & 0.79 & 0.35 & 0.81 & 0.40 & 1.14 & 0.53 & 0.39 & 0.35 & 3.58 \\
\hline & & High & 1.35 & 0.71 & 0.89 & 0.57 & 0.77 & 0.66 & 0.91 & 0.93 & 0.84 & 0.90 & 5.32 \\
\hline \multirow{4}{*}{$\begin{array}{l}\text { Sump } \\
\text { Cut }\end{array}$} & \multirow[t]{2}{*}{ Blowing } & Low & 0.93 & 0.49 & 0.38 & 0.58 & 0.45 & 0.61 & 2.57 & 0.37 & 0.71 & 1.18 & \\
\hline & & High & 1.25 & 0.82 & 0.44 & 0.61 & 0.73 & 0.61 & 3.83 & 0.59 & 1.03 & 1.78 & \\
\hline & \multirow[t]{2}{*}{ Exhausting } & Low & 0.80 & 0.71 & 0.72 & 0.71 & 1.29 & 0.97 & 1.53 & 0.74 & 0.47 & 0.49 & 2.28 \\
\hline & & High & 1.31 & 1.08 & 1.08 & 0.85 & 2.04 & 1.38 & 4.65 & 2.26 & 0.96 & 1.31 & 4.21 \\
\hline
\end{tabular}


Table 3 summarizes the methane concentration results from all test scenarios. The percent difference from average is the difference between the reading at the machinemounted sensor location (MMS) and the average of the means of the face readings (FR) Equation 1. A mean was taken for each of the tests run, and an average of the mean values was then taken to show a better representative value than the average of all of the data collected. Because of outliers in the data, the mean was determined to be a more consistent value than the average. The percent difference from maximum is the difference between the reading at the machine-mounted sensor location (MMS) and the maximum face reading (MF) Equation 2. A negative percent difference indicates that the reading at the machine-mounted sensor is lower than the average or maximum.

Equation 1: Percent difference of the Machine Mounted sensor (MMR) from Average Face readings (FR)

Percent difference from average $=1-\frac{F R}{M M R}$

Equation 2: Percent different of the Machine Mounted sensor (MMR) from the Maximum face reading (MF)

Percent difference from Max $=1-\left(\frac{M F}{M M R}\right)$

Comparing results in 
Table 3, only two scenarios show a lower methane measurement at the machinemounted sensor location than the average face methane: exhausting ventilation, low flow in a slab cut and blowing ventilation, high flow in a sump entry, with differences of $2 \%$ and $23 \%$, respectively. All of the other machine-mounted methanometer location readings are higher than the average face readings. This indicates that the machine mounted location for the methane sensor, in these testing scenarios is adequate for determining average methane concentrations at the face with suitable ventilation at the mining face.

When comparing the maximum methane reading on the face to the machine location, only two cases show higher readings at the machine-mounted sensor location than on the face-both were with blowing ventilation. In the other cases, peak face methane readings range from $4 \%$ to $52 \%$ higher than at the machine-mounted location. 
Table 3: Methane concentration for various face ventilation scenarios

\begin{tabular}{|c|c|c|c|c|c|c|c|}
\hline $\begin{array}{c}\text { Entry Width } \\
\quad \text { Cut }\end{array}$ & $\begin{array}{c}\text { Ventilation } \\
\text { Setup }\end{array}$ & Flow & $\begin{array}{c}\text { Mean } \\
\text { Methanometer } \\
\text { reading } \\
\text { (machine- } \\
\text { mounted sensor } \\
\text { location) \% CH4 }\end{array}$ & $\begin{array}{c}\text { Average } \\
\text { face } \mathrm{CH} 4 \\
\text { readings, } \\
\% \mathrm{CH} 4\end{array}$ & $\begin{array}{c}\text { Maximum } \\
\text { CH4 face } \\
\text { reading } \\
\% \mathrm{CH} 4\end{array}$ & $\begin{array}{c}\text { Percent } \\
\text { Difference } \\
\text { from } \\
\text { Average }\end{array}$ & $\begin{array}{c}\text { Percent } \\
\text { Difference } \\
\text { from } \\
\text { Maximum }\end{array}$ \\
\hline \multirow[t]{4}{*}{ Slab Cut } & \multirow[t]{2}{*}{ Blowing } & Low & 0.36 & 0.25 & 0.37 & $30 \%$ & $-4 \%$ \\
\hline & & High & 0.38 & 0.25 & 0.35 & $36 \%$ & $8 \%$ \\
\hline & \multirow[t]{2}{*}{ Exhausting } & Low & 0.64 & 0.66 & 0.98 & $-2 \%$ & $-52 \%$ \\
\hline & & High & 0.47 & 0.41 & 0.62 & $12 \%$ & $-32 \%$ \\
\hline \multirow[t]{4}{*}{ Sump Cut } & \multirow[t]{2}{*}{ Blowing } & Low & 0.76 & 0.56 & 0.70 & $26 \%$ & $7 \%$ \\
\hline & & High & 0.60 & 0.73 & 0.86 & $-23 \%$ & $-45 \%$ \\
\hline & \multirow[t]{2}{*}{ Exhausting } & Low & 0.81 & 0.75 & 0.95 & $8 \%$ & $-18 \%$ \\
\hline & & High & 0.56 & 0.55 & 0.75 & $1 \%$ & $-35 \%$ \\
\hline
\end{tabular}

Detailed Analysis of Sump Cut, High flow scenarios

The air flow data for this test scenario was looked at in detail for each location as in Figure 8. The Mean, Median, Mode and statistical information was processed for each test to determine if they were significant. The Median was determined to be a better representation of the velocity data when processed. Variation of the airflow made a Mean or Average less accurate with some outliers in the data. Table 5 shows the air flow magnitude statistical analysis for all three runs for Location 1 for the Sump cut, high flow and blowing ventilation set up test. As we can see, the mean and the median are very close. The outliers cause the mean to be higher than the median. Because of the larger spread of the data, the standard deviation is rather high when compared to the Mean. Additionally the range is large due to the point reading ventilation, which is known to vary. Due to these variations in data and the point reading, it was decided that a Median reading of the ventilation velocity was the most accurate value to use when analyzing data. In Table 5 the break up in the data can be identified and the values that were most frequently recorded by the anemometer in the histogram.

Table 4 is a histogram of the velocity direction in degrees recorded for location 1. Location 1 was a good example of an easily attainable direction with the data. Some 
locations like location 4 (Appendix Figure 11) the graphic of the direction degrees shows that the location is between 300-50 degrees, which are within 110 degrees of each other, but in statistical analysis, show a large discrepancy because of the $0-360^{\circ}$ nature of direction. With this data for all points, a Mean and Median do not always determine a good value for the data collected.

Table 4: Location one Histogram for velocity directional degrees

\begin{tabular}{|c|r|}
\hline Bin & Frequency \\
\hline 60.94525 & 1 \\
\hline 67.01775 & 0 \\
\hline 73.09025 & 0 \\
\hline 79.16274 & 0 \\
\hline 85.23524 & 3 \\
\hline 91.30773 & 2 \\
\hline 97.38023 & 4 \\
\hline 103.4527 & 7 \\
\hline 109.5252 & 11 \\
\hline 115.5977 & 9 \\
\hline 121.6702 & 16 \\
\hline 127.7427 & 15 \\
\hline 133.8152 & 30 \\
\hline 139.8877 & 23 \\
\hline 145.9602 & 24 \\
\hline 152.0327 & 27 \\
\hline 158.1052 & 42 \\
\hline 164.1777 & 43 \\
\hline 170.2502 & 29 \\
\hline 176.3227 & 61 \\
\hline 182.3952 & 58 \\
\hline 188.4677 & 76 \\
\hline 194.5402 & 103 \\
\hline 200.6127 & 80 \\
\hline 206.6852 & 28 \\
\hline 212.7577 & 7 \\
\hline & \\
\hline
\end{tabular}


Table 5: Histogram and statistical break down for airflow magnitude $(\mathrm{m} / \mathrm{s})$ for Location 1 of the Sump Cut, High Blow, and Blowing Ventilation test.

\begin{tabular}{|c|c|c|c|}
\hline Bin & Frequency & Location 1 & \\
\hline 0.0232 & 1 & & \\
\hline 0.13597 & 1 & Mean & 1.24525 \\
\hline 0.24874 & 8 & Standard Error & 0.01733 \\
\hline 0.3615 & 9 & Median & 1.22801 \\
\hline 0.47427 & 10 & Mode & 0.90802 \\
\hline 0.58704 & 14 & Standard Deviation & 0.4594 \\
\hline 0.69981 & 33 & Sample Variance & 0.21105 \\
\hline 0.81257 & 47 & Kurtosis & 0.06244 \\
\hline 0.92534 & 44 & Skewness & 0.21299 \\
\hline 1.03811 & 57 & Range & 2.93196 \\
\hline 1.15088 & 86 & Minimum & 0.0232 \\
\hline 1.26365 & 68 & Maximum & 2.95516 \\
\hline 1.37641 & 67 & Sum & 875.412 \\
\hline 1.48918 & 56 & Count & 703 \\
\hline 1.60195 & 55 & Confidence Level(95.0\%) & 0.03402 \\
\hline 1.71472 & 43 & & \\
\hline 1.82748 & 29 & & \\
\hline 1.94025 & 19 & & \\
\hline 2.05302 & 16 & & \\
\hline 2.16579 & 16 & & \\
\hline 2.27856 & 13 & & \\
\hline 2.39132 & 7 & & \\
\hline 2.50409 & 3 & & \\
\hline
\end{tabular}

Determining a good value to use when identifying a direction in the airflow values were significantly harder to identify. Again the data varied, and at time to a point where a direction for the ventilation flow could not be determined by the data that was collected and flow was determined to be turbulent at those points (see location 8, Appendix Figure 15). A majority of the location data points did have a direction that could be recorded and identified. As you can see from location 1 data in Figure 12 this location had a consistent directional flow median of $180^{\circ}$ (Table 6) which from Figure 10 we can determine the velocity is directed towards the face. When determining the value to be used for air flow direction, the mode was determined to be the best fit value when looking at the graphical data and statistical analysis. 


\section{Location 1, Velocity Direction in Degrees}

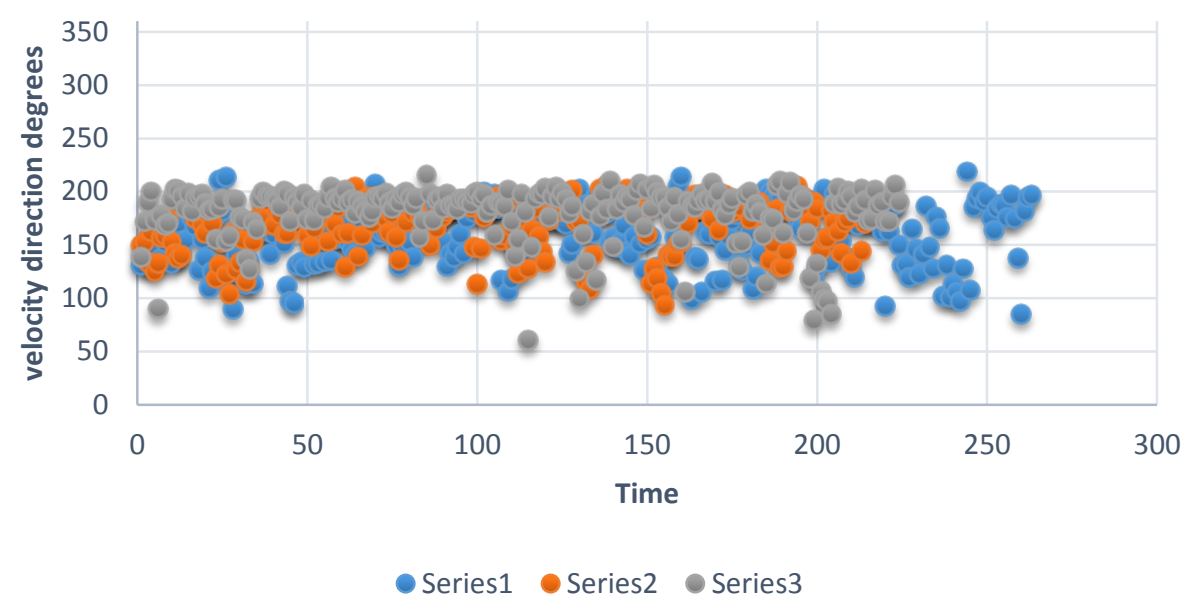

Figure 12: Velocity direction recorded in Degrees for Location 1 of the High flow, Sump Cut, Blowing Ventilation test case. Each series represents a test and the repeats

Table 6 Statistical analysis of Location 1 velocity direction in degrees for the sump cut, high flow, blowing ventilation curtain set up

\begin{tabular}{|l|r|}
\hline \multicolumn{2}{|l|}{ Location 1 Velocity directional degrees } \\
\hline & \\
Mean & 169.200 \\
Standard Error & 1.055 \\
Median & 176.885 \\
Mode & 180.000 \\
Standard Deviation & 27.983 \\
Sample Variance & 783.035 \\
Kurtosis & 0.194 \\
Skewness & -0.912 \\
Range & 157.885 \\
Minimum & 60.945 \\
Maximum & 218.830 \\
Sum & 118947.708 \\
Count & 703.000 \\
Confidence & \\
Level(95.0\%) & 2.072 \\
\hline
\end{tabular}

Using the Median air flow velocity and the Mode of the air flow directional degrees in Table 7 an AutoCAD drawing of the flow patterns for this data was created. Figure 13 shows this information graphically for this test case. Using the Mode for velocity 
direction to get the direction of the airflow in Figure 13, but it was determined for location 8 , that the air is turbulent and a direction will not properly determine the direction of the airfow over time in one direction (Appendix Figure 15). But for visual purposes, the Mode was selected for this point.

Table 7: Mean, Median, Mode and Standard Deviation for each location air flow velocity and directional degrees for the High flow, Sump cut, Blowing ventilation case

\begin{tabular}{|lccccccccccc|}
\hline \multicolumn{10}{c|}{ Air flow Velocity in $\mathbf{~} / \mathbf{s}$} \\
\hline \hline Location & $\mathbf{1}$ & $\mathbf{2}$ & $\mathbf{3}$ & $\mathbf{4}$ & $\mathbf{5}$ & $\mathbf{6}$ & $\mathbf{7}$ & $\mathbf{8}$ & $\mathbf{9}$ & $\mathbf{1 0}$ \\
Mean & 1.24 & 0.82 & 0.44 & 0.61 & 0.73 & 0.61 & 3.82 & 0.59 & 1.04 & 1.78 \\
Median & 1.23 & 0.72 & 0.37 & 0.62 & 0.75 & 0.58 & 3.86 & 0.51 & 0.98 & 1.81 \\
Mode & 0.91 & 0.62 & 0.18 & 0.40 & 0.53 & 1.31 & 3.85 & 0.17 & 0.57 & 1.60 \\
Standard Deviation & 0.46 & 0.54 & 0.32 & 0.22 & 0.27 & 0.34 & 0.23 & 0.40 & 0.57 & 0.68 \\
\hline \multicolumn{10}{c}{ Air flow directional degree } \\
\hline \hline Location & $\mathbf{1}$ & $\mathbf{2}$ & $\mathbf{3}$ & $\mathbf{4}$ & $\mathbf{5}$ & $\mathbf{6}$ & $\mathbf{7}$ & $\mathbf{8}$ & $\mathbf{9}$ & $\mathbf{1 0}$ \\
Mean & 169.2 & 117.8 & 157.6 & 215.5 & 66.6 & 108.6 & 179.9 & 216.0 & 211.5 & 201.4 \\
Median & 176.9 & 54.4 & 117.1 & 330.0 & 26.6 & 81.76 & 181.2 & 220.0 & 207.5 & 199.2 \\
Mode & 180.0 & 45.4 & 90.0 & 346.0 & 360.0 & 30.0 & 182.2 & 330.0 & 178.5 & 221.0 \\
Standard Deviation & 27.9 & 114.4 & 86.2 & 159.5 & 103.9 & 96.8 & 6.0 & 106.4 & 48.2 & 30.0 \\
\hline
\end{tabular}


High Flow, Blowing Ventilation, Sump Cut

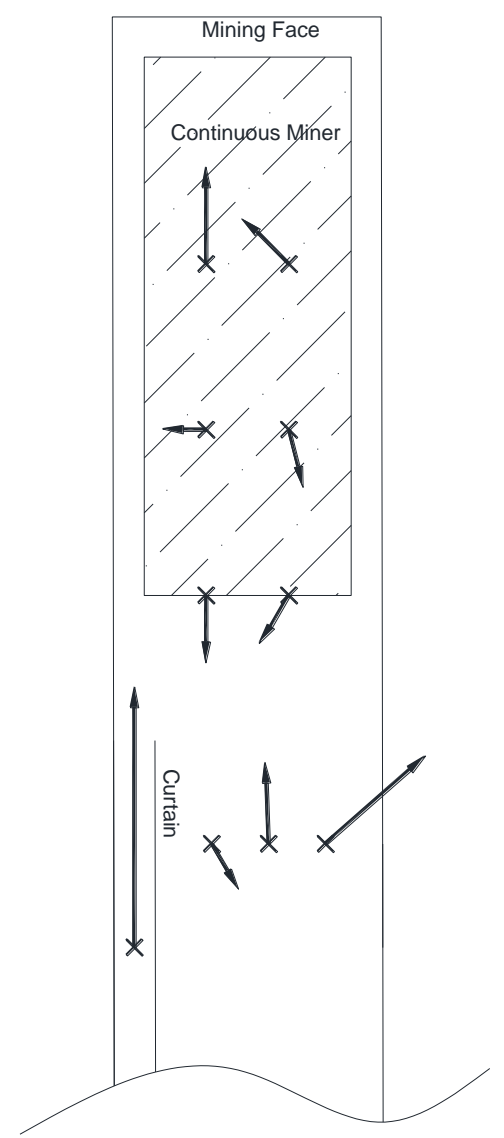

Figure 13: A figure showing air velocity direction, the arrow indicates magnitude. NTS Discussion

In the sump or first cut, the highest methane readings were in the right corner of the cut, indicating that even with the sprays directing air, they also push the methane across the face, which builds up in the right corner. Previous empty-entry monitoring in the ventilation gallery and with CFD modeling (Wala, Vytla et al. 2007, Taylor, Chilton et al. 2010) showed that airflow in a sump cut entry creates a "figure 8" airflow pattern, and higher methane readings were found in the left corner of the entry. Methane data developed in this research ( 
Table 3) suggests a different airflow pattern at the face from the previous empty-entry ventilation flow work, most likely due to the presence of the $\mathrm{CM}$ machine at the face and the use of water sprays and scrubber fan. A more U-shaped airflow pattern across the face is evident. In the slab or second cut entry, a lower methane concentration was shown in the right corner of the face-a result different from the work done in previous laboratory and CFD modeling in an empty entry (Taylor et al. 2010), which showed the highest face methane concentrations at that location. This also suggests that with the $\mathrm{CM}$ at the face, scrubber and water sprays largely affect the flow of the air within the face area in comparison to modeling without these parameters.

In all cases, ventilation velocity on the left side (Location 1 from Figure 8) of the CM was higher than on the right. This indicates that pushing the air from left to right across the

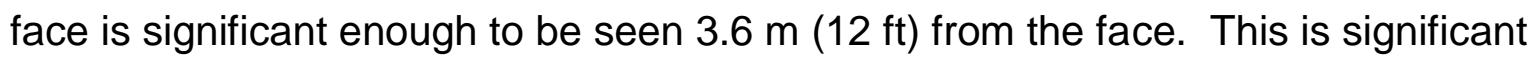
because regardless of whether the air is being directed by a blowing curtain or an exhausting curtain, the left to right airflow is consistent.

As in previous research (Schlick and Dalzell 1963, Dalzell 1966), tests supported the conclusion that blowing curtain ventilation was more efficient in moving fresh air to the face and sweeping away methane than exhausting curtain ventilation. This same result is shown in this research by lower methane readings shown in the blowing curtain setup by comparison to the exhaust curtain setup (Table 3). An exception was in the high flow ventilation case for the slab cut, where methane values were higher in the blowing curtain case than the exhausting, possibly due to the higher air velocity in the smaller entry causing more turbulence, resulting in less effective airflow to dilute and remove methane. A more thorough analysis of airflow, possibly via a CFD program, would detail why this situation occurs.

Only one case showed average face methane readings to be significantly higher than with the machine-mounted methanometer. The blowing ventilation, high flow, sump cut entry test case showed an average face methane concentration of $0.73 \%$, which was $23 \%$ higher than the machine-mounted methanometer reading of $0.60 \%$. All other cases showed methane readings close to or higher at the machine methanometer than 
face location averages, indicating effective placement of the machine-mounted methanometer when compared to actual average face readings.

Comparing maximum face methane readings to actual machine-mounted sensor readings, only two maximums fell below the reading at the machine sensor. The face maximum ranged from $4 \%$ to $52 \%$ higher than at the machine-mounted methanometer, indicating that when the machine sensor methane readings are $2.0 \%$, face locations could have a methane concentration $50 \%$ higher than at the machine mounted methanometer, or over $3.0 \%$. These values show that under these test conditions, a $2 \%$ methane reading at the monitor would have shut off equipment power well below the $5 \%$ lower explosive limit. 


\section{Chapter 5: Conclusions and Recommendations}

Full-scale testing for examining distributions of airflow and methane concentration was conducted in a deep cut continuous miner face simulator using blowing and exhausting ventilation. Technologies such as ultrasonic anemometers allows digital recording of ventilation patterns in and around the face in the laboratory environment provides a significant opportunity to expand research knowledge of ventilation flow around the critical mining face area. The deep cut face has the lowest airflow quantity to the face, is furthest away from the auxiliary ventilation, and has the highest potential for a methane buildup at the face.

Laboratory testing allow us to regulate inputs to better understand what each variable controls allowing better understanding of their effects. It also allows us to collect detailed information for use in verifying highly detailed CFD model for a CM face. Some variables that are not tested in the laboratory need to be taken into consideration when applying these results in an underground mine. An example of a variable seen underground that would not be considered in the laboratory is a plugged or partially plugged scrubber filter. These issues need to be taken into consideration when applying to a coal mine setting.

Based on the analysis of two different entry widths or cut sequences, it is found that the highest methane reading is in the right corner of the narrower entry or sump cuts. This indicates an airflow path which travels directly up the left side of the mining machine and across the face from left to right. Corners of the mining entry are the hardest area of the face to ventilate effectively, and have the greatest likelihood of accumulating contaminants. In this testing, the slab cut ventilation flow shows that lower face methane readings were consistently in the right corner. This indicates that this corner is getting more fresh air than in the sump cut case, with the slab cut entry possibly encouraging a "figure 8" airflow pattern above the miner as shown in previous CFD modeling (Wala, Vytla et al. 2007, Taylor, Chilton et al. 2010).

This work confirms previous laboratory research that blowing curtain ventilation is more efficient at moving fresh air to the face than exhaust curtain ventilation even with the $\mathrm{CM}$ machine at the face. There was an exception in the high flow ventilation case for the 
sump cut entry, where methane values were higher in the blowing curtain case than the exhausting case. The blowing ventilation, high flow, sump cut entry case shows that the average face methane concentration was much higher than the mean machinemounted methanometer reading.

More work should be done to examine face ventilation with the $\mathrm{CM}$ in place and incorporate other factors such as variations in scrubbers and sprays. These issues have been studied separately, but never combined with CFD computer modeling and full-scale testing for verification and validation. Information can be gathered and used to validate highly detailed CFD modeling for airflow in a deep cut scenario, a critical challenge for ventilation engineers.

Future work is recommended to better explain the airflow around mining machine obstructions in the face and the effect of the water sprays and scrubber flow. Goodman and Taylor (Goodman and Taylor 1993, Taylor and Goodman 1997) concluded that the methane concentration error at the machine-mounted methane sensor was influenced primarily by the location of the mining machine at the face. These laboratory tests do not take into consideration issues such as operators standing in front of a blowing curtain, positioning of operators, other operating equipment in the entry, or crosscut ventilation. Limitations of the ventilation gallery and monitoring equipment are that they give a basic understanding of a more detailed ventilation scheme and methane dilution in a static laboratory setting. 


\section{References:}

CFR (2011). Code of Federal Regulations. O. o. t. F. Register. Washington, DC, U.S. Government Printing office. 30.

Colinet, J., J. M. Listak, J. A. Organiscak, J. P. Rider and A. L. Wolfe (2010). Best practices for dust control in coal mining, Department of Health and Human Services, Centers for Disease Control and Prevention, National Institute for Occupational Safety and Health, Office of Mine Safety and Health Research.

Dalzell, R. W. (1966). Face ventilation in underground bituminous coal mines, performance characteristics of common jute line brattice, Bureau of Mines, Washington, DC (USA).

Goodman, G. V. and C. D. Taylor (1993). "Effectiveness of methane monitoring for estimating face gas conditions during deep cutting." Journal of the Mine Ventilation Society of South Africa 46(6): 86-92.

Hall, E., C. Taylor and J. Chilton (2007). Using ultrasonic anemometers to evaluate face ventilation conditions. Proceedings of the SME Annual Meeting and Exhibit.

Hargreaves, D. M. and I. S. Lowndes (2007). "The computational modeling of the ventilation flows within a rapid development drivage." Tunnelling and Underground Space Technology 22(2): 150-160.

Kissell, F. (1979). "Improved face ventilation by spray jet systems." Second Annual Mining Institute, University of Alabama.

Kissell, F. N. (2003). "Dust control methods in tunnels and underground mines." Handbook for dust control in mining. Pittsburgh, PA: US Department of Health and Human Services, Centers for Disease Control and Prevention, National Institute for Occupational Safety and Health, DHHS (NIOSH) Publication(2003-147): 3-21.

Kissell, F. N., J. Banfield Jr, R. Dalzell and M. Zabetakis (1974). Peak Methane Concentrations During Coal Mining: An Analysis, US Bureau of Mines.

Martikainen, A., H. Dougherty, C. Taylor and A. Mazzella (2010). Sonic anemometer airflow monitoring technique for use in underground mines. Proceedings of the 13th US/North American Mine Ventilation Symposium.

Martikainen, A., C. Taylor and A. Mazzella (2011). Effects of obstructions, sample size and sample rate on ultrasonic anemometer measurements underground. SME Annual Meeting, Pre-Print.

Matta, J. E. (1976). Effect of location and type of water sprays for respirable dust suppression on a continuous-mining machine, US Dept. of the Interior, Bureau of Mines.

Petrov, T. and A. Wala (2014). Improvement of blowing curtain face ventilation systems using passive regulator. SME Annual Meeting, Salt Lake City, Utah, SME.

Schlick, D. P. and R. W. Dalzell (1963). Ventilation of continuous-miner places in coal mines, Bureau of Mines, Washington, DC (USA).

Stahl, R. W. (1958). Auxiliary ventilation of continuous miner places, Bureau of Mines, Washington, DC (USA). 
Taylor, C., J. Chilton and G. Goodman (2010). "Guidelines for the Control and Monitoring of Methane Gas on Continuous Mining Operations." DHHS (NIOSH) Publication(2010-141): 1-75.

Taylor, C., J. Chilton and T. Mal (2002). Evaluating performance characteristics of machine-mounted methane monitors by measuring response time. Proc. 9th US Mine Vent Symp.

Taylor, C., J. Chilton and T. Mal (2002). Evaluating performance characteristics of machine-mounted methane monitors by measuring response time. Proceedings, 9th US/NA Mine Ventila tion Symposium, Queens University, Kingston, ON, Canada, June 8Г12, Lisse, AA Balkema.

Taylor, C., R. Timko, M. Senk and A. Lusin (2004). "Measurement of airflow in a simulated undeground mine environment using an ultrasonic anemometer." TRANSACTIONS-SOCIETY FOR MINING METALLURGY AND EXPLORATION INCORPORATED 316: 201.

Taylor, C. D. and G. V. Goodman (1997). "Use of methane monitors for estimating face gas conditions." Applied occupational and environmental hygiene 12(12): 947-951.

Taylor, C. D., R. J. Timko, E. D. Thimons and T. Mal (2007). "Using ultrasonic anemometers to evaluate factors affecting face ventilation effectiveness." TRANSACTIONS-SOCIETY FOR MINING METALLURGY AND EXPLORATION INCORPORATED 320: 127.

Thimons, E. D., C. D. Taylor and J. A. Zimmer (1999). "Ventilating the box cut of a two-pass $40 \mathrm{ft}$ extended cut." Journal of the Mine Ventilation Society of South Africa 52(3): 108-115.

Unwin, I. D. (November 2007). The Measurement of Air Flow

in British Coal Mines: A

Historical Review. http://www.cmhrc.co.uk/cms/document/air flow 2007.pdf, The Coalmining History Resource Centre: 88.

Volkwein, J. and E. Thimons (1986). Extended advance of continuous miner successfully ventilated with a scrubber in a blowing section, Society of Mining Engineers of AIME, Littleton, CO.

Wala, A., V. S, H. G and C. Taylor (2008). Study on the effects of scrubber operation on the face ventilation. 12th U.S./North American Mine Ventilation Symposium. K. Wallace Jr, SME: 281-286.

Wala, A., S. Vytla, C. Taylor and G. Huang (2007). "Mine face ventilation: a comparison of CFD results against benchmark experiments for the CFD code validation." Mining Engineering 59(10): 49-55. 


\section{Appendix A}

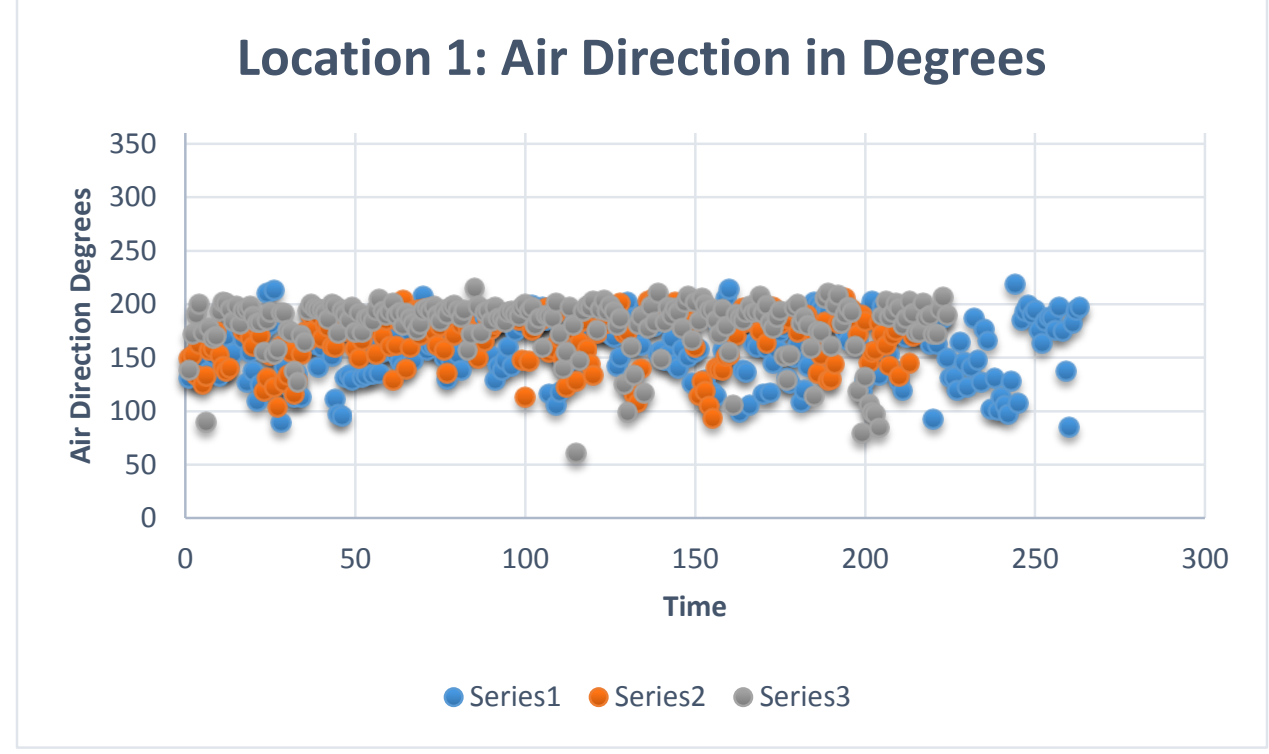

Appendix Figure 1: Graphical data of Velocity direction in degrees over time for the three different repeat tests run

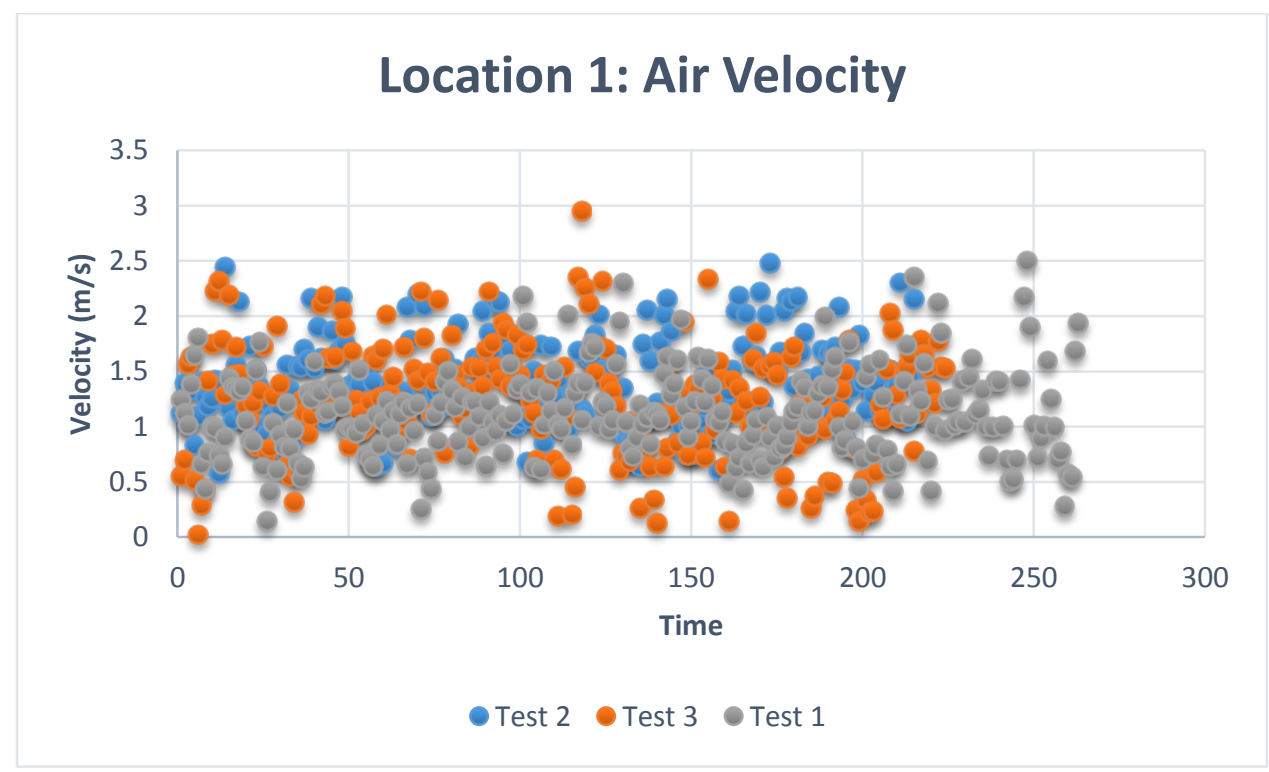

Appendix Figure 2: Graphical data of air velocity magnitude $(\mathrm{m} / \mathrm{s})$ over time for the three repeat tests run 


\begin{tabular}{|c|c|c|c|}
\hline \multicolumn{2}{|c|}{ Location 1 Degrees } & \multicolumn{2}{|c|}{ Location 1 Velocity } \\
\hline Mean & 169.2002 & Mean & 1.245251 \\
\hline Standard Error & 1.05539 & Standard Error & 0.017327 \\
\hline Median & 176.8845 & Median & 1.228007 \\
\hline Mode & 180.0004 & Mode & 0.90802 \\
\hline Standard Deviation & 27.98276 & Standard Deviation & 0.459405 \\
\hline Sample Variance & 783.0347 & Sample Variance & 0.211053 \\
\hline Kurtosis & 0.193931 & Kurtosis & 0.062441 \\
\hline Skewness & -0.91204 & Skewness & 0.212987 \\
\hline Range & 157.8849 & Range & 2.931962 \\
\hline Minimum & 60.94525 & Minimum & 0.0232 \\
\hline Maximum & 218.8302 & Maximum & 2.955162 \\
\hline Sum & 118947.7 & Sum & 875.4115 \\
\hline Count & 703 & Count & 703 \\
\hline Level(95.0\%) & 2.072098 & Level(95.0\%) & 0.034019 \\
\hline
\end{tabular}

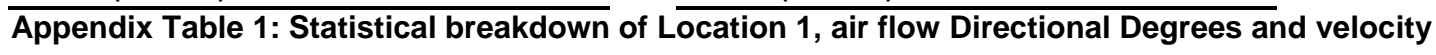




\begin{tabular}{|c|c|c|c|}
\hline \multicolumn{2}{|c|}{ Location 1 Velocity } & \multicolumn{2}{|c|}{ Location 1 Degrees } \\
\hline Bin & Frequency & Bin & Frequency \\
\hline 0.0232 & 1 & 60.94525 & 1 \\
\hline 0.135968 & 1 & 67.01775 & 0 \\
\hline 0.248736 & 8 & 73.09025 & 0 \\
\hline 0.361503 & 9 & 79.16274 & 0 \\
\hline 0.474271 & 10 & 85.23524 & 3 \\
\hline 0.587039 & 14 & 91.30773 & 2 \\
\hline 0.699807 & 33 & 97.38023 & 4 \\
\hline 0.812575 & 47 & 103.4527 & 7 \\
\hline 0.925342 & 44 & 109.5252 & 11 \\
\hline 1.03811 & 57 & 115.5977 & 9 \\
\hline 1.150878 & 86 & 121.6702 & 16 \\
\hline 1.263646 & 68 & 127.7427 & 15 \\
\hline 1.376413 & 67 & 133.8152 & 30 \\
\hline 1.489181 & 56 & 139.8877 & 23 \\
\hline 1.601949 & 55 & 145.9602 & 24 \\
\hline 1.714717 & 43 & 152.0327 & 27 \\
\hline 1.827485 & 29 & 158.1052 & 42 \\
\hline 1.940252 & 19 & 164.1777 & 43 \\
\hline 2.05302 & 16 & 170.2502 & 29 \\
\hline 2.165788 & 16 & 176.3227 & 61 \\
\hline 2.278556 & 13 & 182.3952 & 58 \\
\hline 2.391324 & 7 & 188.4677 & 76 \\
\hline 2.504091 & 3 & 194.5402 & 103 \\
\hline 2.616859 & 0 & 200.6127 & 80 \\
\hline 2.729627 & 0 & 206.6852 & 28 \\
\hline 2.842395 & 0 & 212.7577 & 7 \\
\hline
\end{tabular}

Appendix Table 2: Histogram of Location 1, air flow directional degrees (in 0-360 degrees) and velocity (in $\mathbf{m} / \mathbf{s})$

Location 2: 


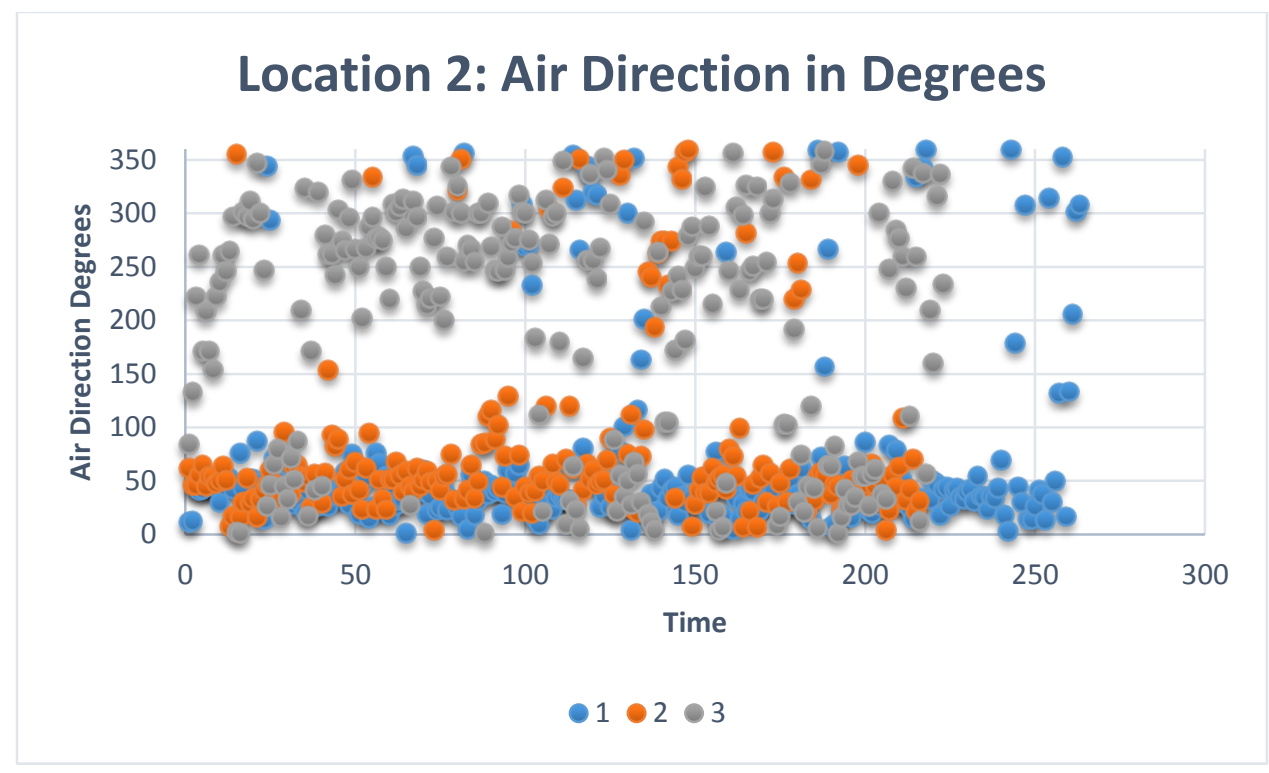

Appendix Figure 3: Graphical data of air velocity direction in degrees over time for the three test repeats

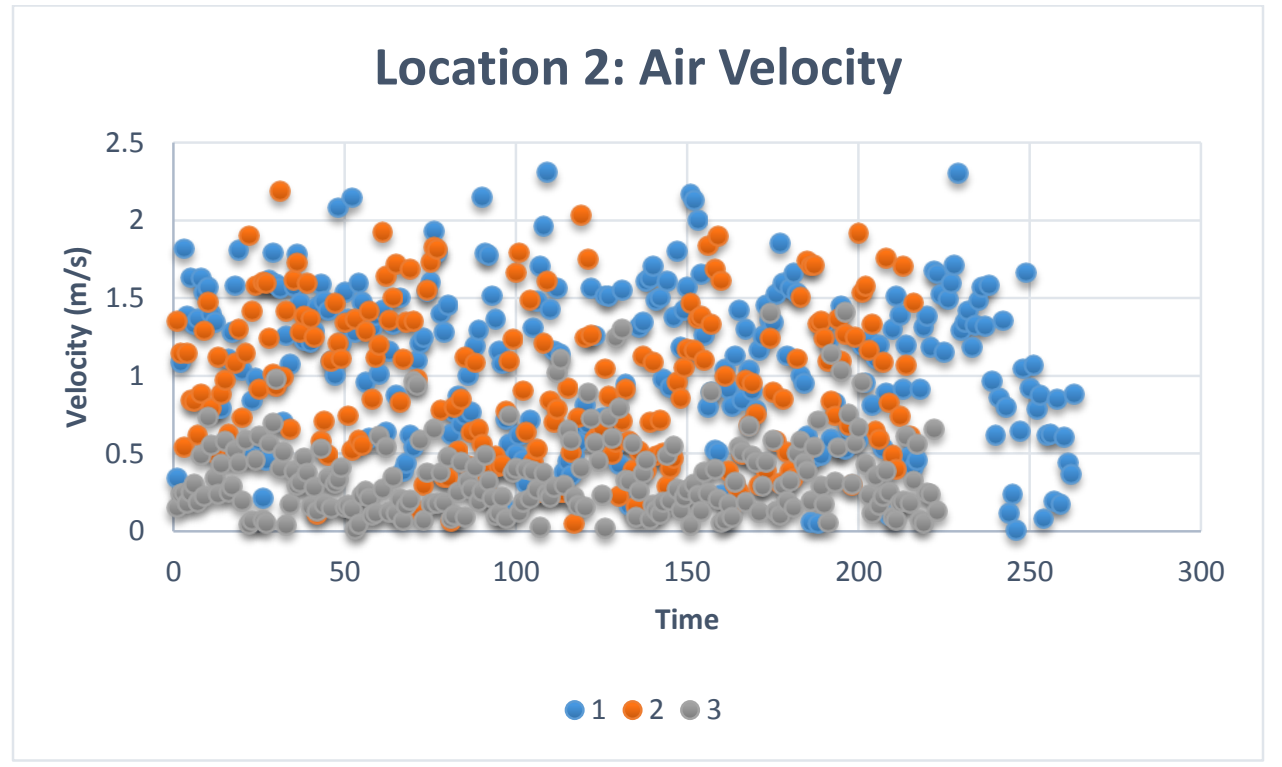

Appendix Figure 4: Graphical data of air velocity magnitude $(\mathrm{m} / \mathrm{s})$ over time for the three test repeats 


\begin{tabular}{|c|c|c|c|}
\hline \multicolumn{2}{|c|}{ Location 2 Directional Degrees } & \multicolumn{2}{|c|}{ Location 2 Air Velocity } \\
\hline Mean & 117.8189493 & Mean & 0.821566 \\
\hline Standard Error & 4.182717836 & Standard Error & 0.020281 \\
\hline Median & 54.40384901 & Median & 0.718503 \\
\hline Mode & 45.37618096 & Mode & 0.618466 \\
\hline Standard Deviation & 114.4720544 & Standard Deviation & 0.537354 \\
\hline Sample Variance & 13103.85124 & Sample Variance & 0.28875 \\
\hline Kurtosis & 0.846723373 & Kurtosis & -0.8916 \\
\hline Skewness & 0.903064494 & Skewness & 0.40694 \\
\hline Range & 358.9533021 & Range & 2.298679 \\
\hline Minimum & 0.945405258 & Minimum & 0.01 \\
\hline Maximum & 359.8987073 & Maximum & 2.308679 \\
\hline Sum & 88246.39301 & Sum & 576.7391 \\
\hline Count & 749 & Count & 702 \\
\hline Confidence & & Confidence & \\
\hline Level(95.0\%) & 8.211262871 & Level(95.0\%) & 0.039819 \\
\hline
\end{tabular}

Appendix Table 3: Statistical breakdown of Location 2, air flow directional degrees and velocity 


\begin{tabular}{|c|c|c|c|}
\hline \multicolumn{2}{|c|}{ Location 2 Velocity } & \multicolumn{2}{|c|}{ Location 2 Direction } \\
\hline Bin & Frequency & Bin & Frequency \\
\hline 0.01 & 1 & 0.945405 & 1 \\
\hline 0.098411 & 30 & 14.23997 & 35 \\
\hline 0.186821 & 51 & 27.53454 & 94 \\
\hline 0.275232 & 55 & 40.82911 & 111 \\
\hline 0.363643 & 40 & 54.12367 & 131 \\
\hline 0.452053 & 46 & 67.41824 & 74 \\
\hline 0.540464 & 46 & 80.71281 & 26 \\
\hline 0.628875 & 52 & 94.00737 & 16 \\
\hline 0.717286 & 30 & 107.3019 & 11 \\
\hline 0.805696 & 30 & 120.5965 & 12 \\
\hline 0.894107 & 26 & 133.8911 & 4 \\
\hline 0.982518 & 29 & 147.1856 & 0 \\
\hline 1.070929 & 18 & 160.4802 & 5 \\
\hline 1.159339 & 33 & 173.7748 & 6 \\
\hline 1.24775 & 29 & 187.0693 & 4 \\
\hline 1.336161 & 33 & 200.3639 & 4 \\
\hline 1.424572 & 36 & 213.6585 & 8 \\
\hline 1.512982 & 26 & 226.953 & 10 \\
\hline 1.601393 & 31 & 240.2476 & 13 \\
\hline 1.689804 & 19 & 253.5422 & 18 \\
\hline 1.778214 & 12 & 266.8367 & 27 \\
\hline 1.866625 & 13 & 280.1313 & 23 \\
\hline 1.955036 & 5 & 293.4259 & 10 \\
\hline 2.043447 & 3 & 306.7204 & 28 \\
\hline 2.131857 & 2 & 320.015 & 19 \\
\hline 2.220268 & 4 & 333.3096 & 15 \\
\hline & & 346.6041 & 22 \\
\hline
\end{tabular}

Appendix Table 4: Histogram of Location 2, air flow directional degrees and velocity $(\mathrm{m} / \mathrm{s})$

Location 3: 


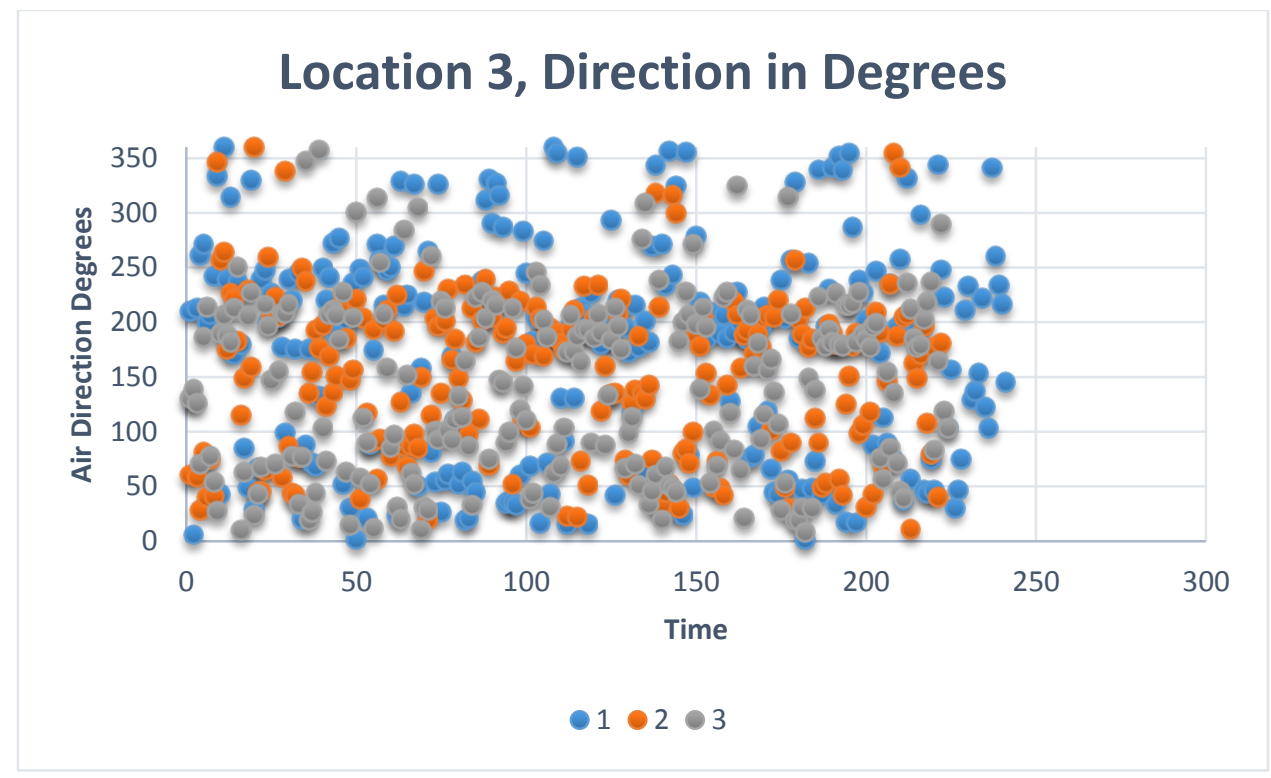

Appendix Figure 5: Graphical data of air velocity direction in degrees over time for the three test repeats

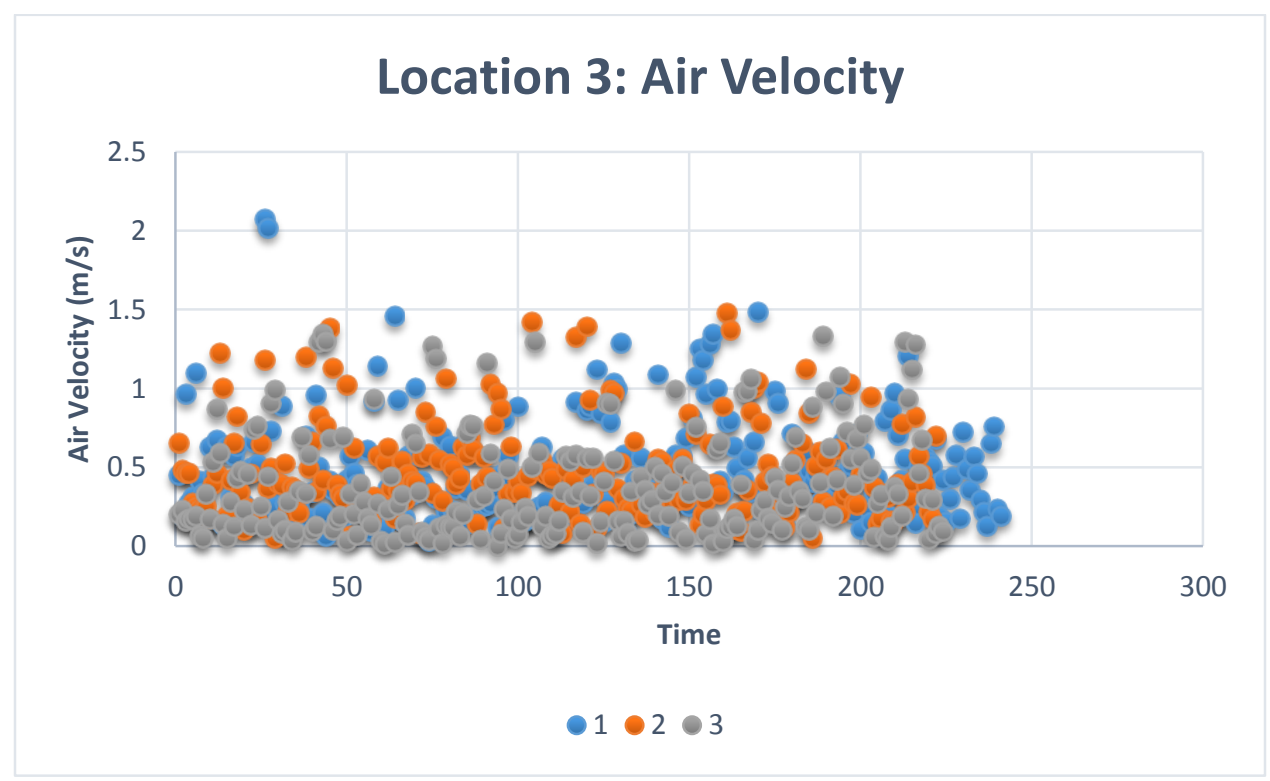

Appendix Figure 6: Graphical data of air velocity magnitude $(\mathrm{m} / \mathrm{s})$ over time for three test repeats 


\begin{tabular}{lrrlrr}
\hline \multicolumn{2}{c}{ Location 3 Air Velocity } & & & \multicolumn{2}{c}{ Location 3 Directional Degree } \\
\cline { 1 - 1 } \cline { 5 - 5 } Mean & & & & \\
Standard Error & 0.445707 & & Mean & 157.5965 \\
Median & 0.012255 & & Standard Error & 3.290584 \\
Mode & 0.37 & & Median & 177.1372 \\
Standard Deviation & 0.180278 & & Mode & 89.99979 \\
Sample Variance & 0.321217 & & Standard Deviation & 86.24847 \\
Kurtosis & 0.10318 & & Sample Variance & 7438.798 \\
Skewness & 2.061882 & & Kurtosis & -0.7093 \\
Range & 1.312222 & & Skewness & 0.138551 \\
Minimum & 2.068469 & & Range & 358.6361 \\
Maximum & 0.0024 & & Minimum & 1.363924 \\
Sum & 2.070869 & & Maximum & 360 \\
Count & 306.2009 & & Sum & 108268.8 \\
Confidence Level(95.0\%) & 0.024062 & & Confidence Level(95.0\%) & 6.460826 \\
\hline Appendix Table 5: Statistical breakdown & of & Location 3, air flow directional degrees and &
\end{tabular}

Appendix Table 5: Statistical breakdown of Location 3, air flow directional degrees and velocity 


\begin{tabular}{|c|c|c|c|}
\hline \multicolumn{2}{|c|}{ Location 3 Velocity } & \multicolumn{2}{|c|}{ Location 3 Direction } \\
\hline Bin & Frequency & Bin & Frequency \\
\hline 0.0024 & 1 & 1.363924 & 1 \\
\hline 0.081957 & 40 & 15.15762 & 8 \\
\hline 0.161513 & 76 & 28.95131 & 28 \\
\hline 0.24107 & 93 & 42.74501 & 32 \\
\hline 0.320626 & 79 & 56.53871 & 48 \\
\hline 0.400183 & 87 & 70.3324 & 32 \\
\hline 0.479739 & 67 & 84.1261 & 35 \\
\hline 0.559296 & 50 & 97.91979 & 28 \\
\hline 0.638852 & 47 & 111.7135 & 25 \\
\hline 0.718409 & 33 & 125.5072 & 20 \\
\hline 0.797965 & 19 & 139.3009 & 29 \\
\hline 0.877522 & 14 & 153.0946 & 17 \\
\hline 0.957078 & 18 & 166.8883 & 21 \\
\hline 1.036635 & 22 & 180.682 & 36 \\
\hline 1.116191 & 7 & 194.4757 & 63 \\
\hline 1.195748 & 9 & 208.2694 & 70 \\
\hline 1.275304 & 5 & 222.063 & 53 \\
\hline 1.354861 & 11 & 235.8567 & 37 \\
\hline 1.434417 & 4 & 249.6504 & 27 \\
\hline 1.513974 & 3 & 263.4441 & 13 \\
\hline 1.59353 & 0 & 277.2378 & 12 \\
\hline 1.673087 & 0 & 291.0315 & 7 \\
\hline 1.752643 & 0 & 304.8252 & 4 \\
\hline 1.8322 & 0 & 318.6189 & 9 \\
\hline 1.911756 & 0 & 332.4126 & 10 \\
\hline 1.991313 & 0 & 346.2063 & 9 \\
\hline More & 2 & More & 13 \\
\hline
\end{tabular}

Appendix Table 6: Histogram of Location 3, air flow directional degrees and velocity $(\mathrm{m} / \mathrm{s})$

Location 4: 


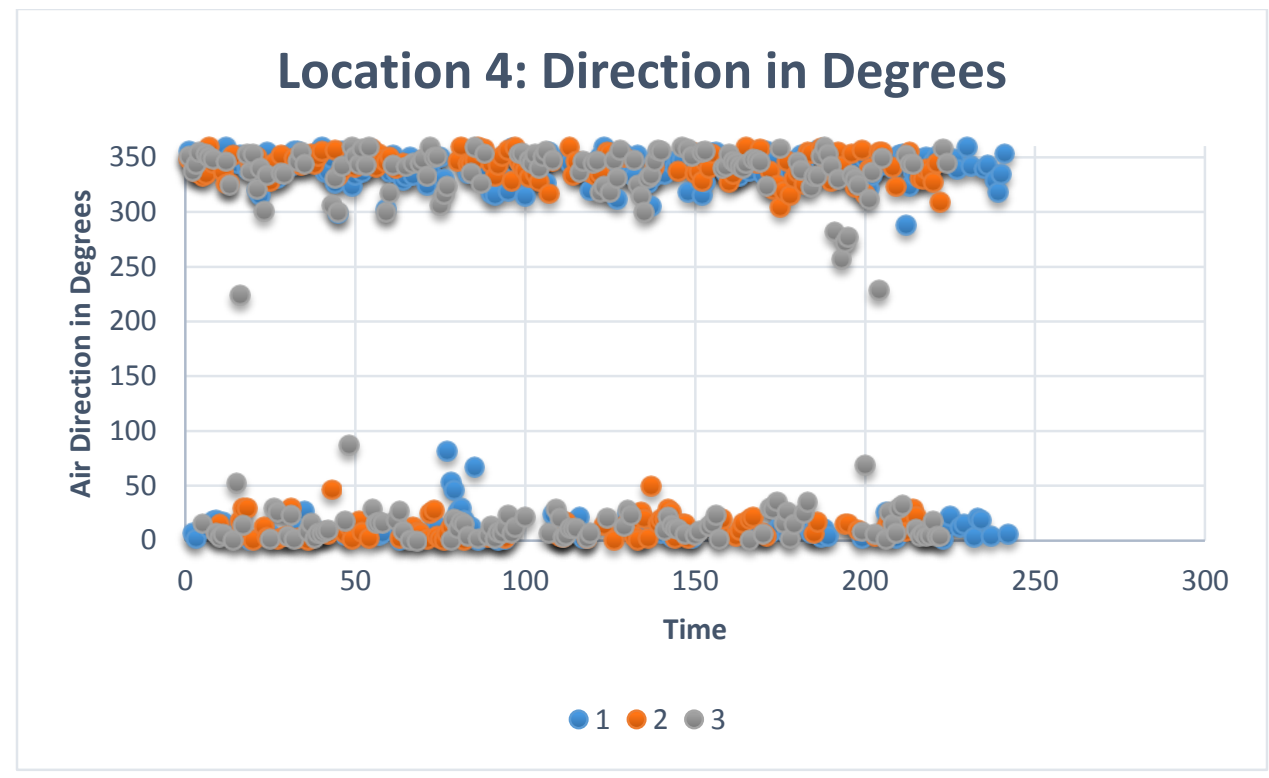

Appendix Figure 7: Graphical data of velocity direction in degrees over time for the three test repeats

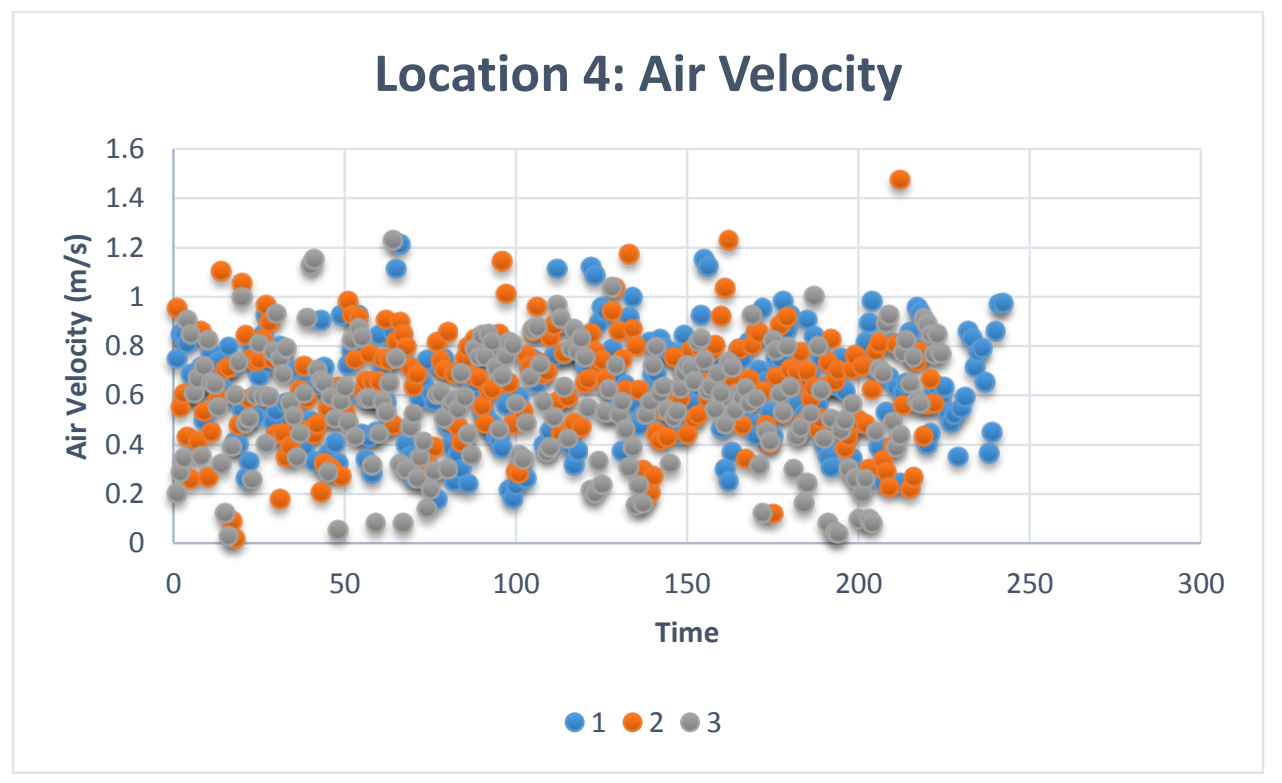

Appendix Figure 8: Graphical data of air velocity magnitude $(\mathrm{m} / \mathrm{s})$ over time for the three test repeats 


\begin{tabular}{|c|c|c|c|}
\hline \multicolumn{2}{|c|}{ Location 4 Air Velocity } & \multicolumn{2}{|c|}{ Location 4 Directional Degree } \\
\hline Mean & 0.608751 & Mean & 215.4974 \\
\hline Standard Error & 0.008609 & Standard Error & 6.080095 \\
\hline Median & 0.619314 & Median & 330.9947 \\
\hline Mode & 0.403113 & Mode & 346.0051 \\
\hline Standard Deviation & 0.225807 & Standard Deviation & 159.4794 \\
\hline Sample Variance & 0.050989 & Sample Variance & 25433.68 \\
\hline Kurtosis & 0.023702 & Kurtosis & -1.74427 \\
\hline Skewness & -0.03061 & Skewness & -0.48055 \\
\hline Range & 1.456279 & Range & 359.8804 \\
\hline Minimum & 0.02 & Minimum & 0.018324 \\
\hline Maximum & 1.476279 & Maximum & 359.8987 \\
\hline Sum & 418.8209 & Sum & 148262.2 \\
\hline Count & 688 & Count & 688 \\
\hline Confidence Level(95.0\%) & 0.016903 & Confidence Level(95.0\%) & 11.9378 \\
\hline
\end{tabular}

Appendix Table 7: Statistical breakdown of Location 4 air flow directional degrees and velocity 


\begin{tabular}{|c|c|c|c|}
\hline \multicolumn{2}{|c|}{ Location 4 Velocity } & \multicolumn{2}{|c|}{ Location 4 Direction } \\
\hline Bin & Frequency & Bin & Frequency \\
\hline 0.02 & 1 & 0.018324 & 1 \\
\hline 0.076011 & 4 & 13.85988 & 162 \\
\hline 0.132022 & 10 & 27.70143 & 73 \\
\hline 0.188033 & 8 & 41.54298 & 17 \\
\hline 0.244043 & 15 & 55.38454 & 5 \\
\hline 0.300054 & 30 & 69.22609 & 2 \\
\hline 0.356065 & 35 & 83.06764 & 1 \\
\hline 0.412076 & 33 & 96.9092 & 1 \\
\hline 0.468086 & 47 & 110.7507 & 0 \\
\hline 0.524097 & 55 & 124.5923 & 0 \\
\hline 0.580108 & 56 & 138.4339 & 0 \\
\hline 0.636118 & 74 & 152.2754 & 0 \\
\hline 0.692129 & 61 & 166.117 & 0 \\
\hline 0.74814 & 63 & 179.9585 & 0 \\
\hline 0.804151 & 67 & 193.8001 & 0 \\
\hline 0.860161 & 51 & 207.6416 & 0 \\
\hline 0.916172 & 27 & 221.4832 & 0 \\
\hline 0.972183 & 24 & 235.3247 & 2 \\
\hline 1.028193 & 8 & 249.1663 & 0 \\
\hline 1.084204 & 4 & 263.0078 & 1 \\
\hline 1.140215 & 7 & 276.8494 & 1 \\
\hline 1.196226 & 4 & 290.6909 & 3 \\
\hline 1.252236 & 3 & 304.5325 & 6 \\
\hline 1.308247 & 0 & 318.374 & 20 \\
\hline 1.364258 & 0 & 332.2156 & 55 \\
\hline 1.420269 & 0 & 346.0572 & 164 \\
\hline More & 1 & More & 174 \\
\hline
\end{tabular}

Appendix Table 8: Histogram of Location 4 air flow directional degrees and velocity $(\mathrm{m} / \mathrm{s})$

Location 5: 


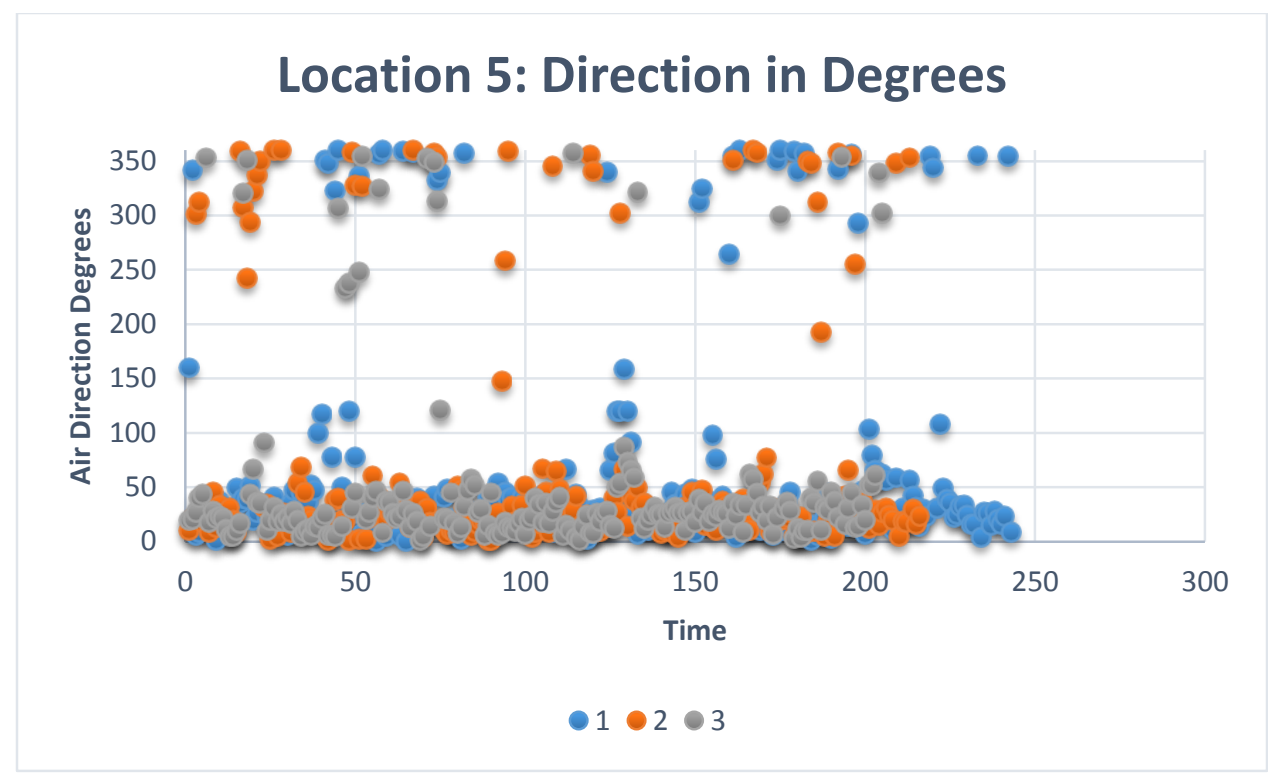

Appendix Figure 9: Graphical data of velocity direction in degrees over time for the three test repeats

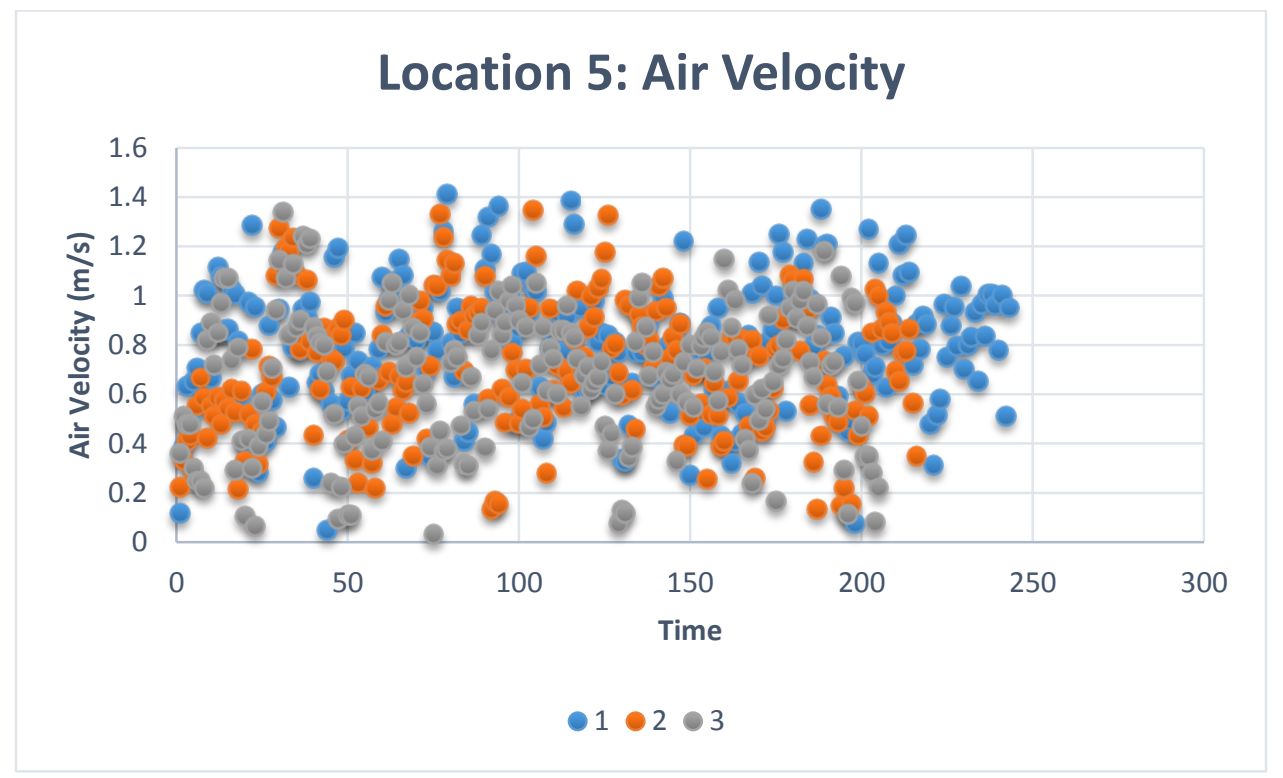

Appendix Figure 10: Graphical data of air velocity magnitude $(\mathrm{m} / \mathrm{s})$ over time for the three test repeats 


\begin{tabular}{|c|c|c|c|}
\hline \multicolumn{2}{|c|}{ Location 5 Air Velocity } & \multicolumn{2}{|c|}{ Location 5 Directional Degree } \\
\hline Mean & 0.730029 & Mean & 66.6029 \\
\hline Standard Error & 0.010635 & Standard Error & 4.03408 \\
\hline Median & 0.753724 & Median & 26.56499 \\
\hline Mode & 0.533385 & Mode & 360 \\
\hline Standard Deviation & 0.274036 & Standard Deviation & 103.951 \\
\hline Sample Variance & 0.075096 & Sample Variance & 10805.8 \\
\hline Kurtosis & -0.33162 & Kurtosis & 2.968152 \\
\hline Skewness & -0.17307 & Skewness & 2.154056 \\
\hline Range & 1.380174 & Range & 359.5018 \\
\hline Minimum & 0.032129 & Minimum & 0.49821 \\
\hline Maximum & 1.412303 & Maximum & 360 \\
\hline Sum & 484.7392 & Sum & 44224.32 \\
\hline Count & 664 & Count & 664 \\
\hline Confidence Level(95.0\%) & 0.020882 & Confidence Level(95.0\%) & 7.921112 \\
\hline
\end{tabular}




\begin{tabular}{|c|c|c|c|}
\hline \multicolumn{2}{|c|}{ Location 5 Velocity } & \multicolumn{2}{|c|}{ Locaiton 5 Degree } \\
\hline Bin & Frequency & Bin & Frequency \\
\hline 0.032129 & 1 & 0.49821 & L \\
\hline 0.087336 & 5 & 14.87828 & 152 \\
\hline 0.142543 & 11 & 29.25835 & 215 \\
\hline 0.19775 & 5 & 43.63843 & 119 \\
\hline 0.252957 & 12 & 58.0185 & 52 \\
\hline 0.308164 & 13 & 72.39857 & 18 \\
\hline 0.363371 & 21 & 86.77864 & + \\
\hline 0.418577 & 26 & 101.1587 & 7 \\
\hline 0.473784 & 28 & 115.5388 & 3 \\
\hline 0.528991 & 36 & 129.9189 & 6 \\
\hline 0.584198 & 40 & 144.2989 & 0 \\
\hline 0.639405 & 42 & 158.679 & 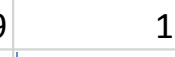 \\
\hline 0.694612 & 47 & 173.0591 & 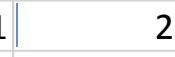 \\
\hline 0.749819 & 40 & 187.4391 & 0 \\
\hline 0.805026 & 54 & 201.8192 & 1 \\
\hline 0.860233 & 63 & 216.1993 & 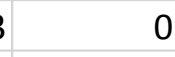 \\
\hline 0.91544 & 48 & 230.5794 & 0 \\
\hline 0.970647 & 46 & 244.9594 & 3 \\
\hline 1.025854 & 40 & 259.3395 & 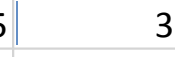 \\
\hline 1.081061 & 28 & 273.7196 & 5 \\
\hline 1.136268 & 15 & 288.0996 & $v$ \\
\hline 1.191475 & 14 & 302.4797 & 6 \\
\hline 1.246682 & 12 & 316.8598 & 0 \\
\hline 1.301889 & 8 & 331.2399 & 8 \\
\hline 1.357096 & 6 & 345.6199 & 12 \\
\hline More & 3 & More & 44 \\
\hline
\end{tabular}

Appendix Table 10: Histogram of location 5 air flow directional degrees and velocity $(\mathrm{m} / \mathrm{s})$

Location 6: 


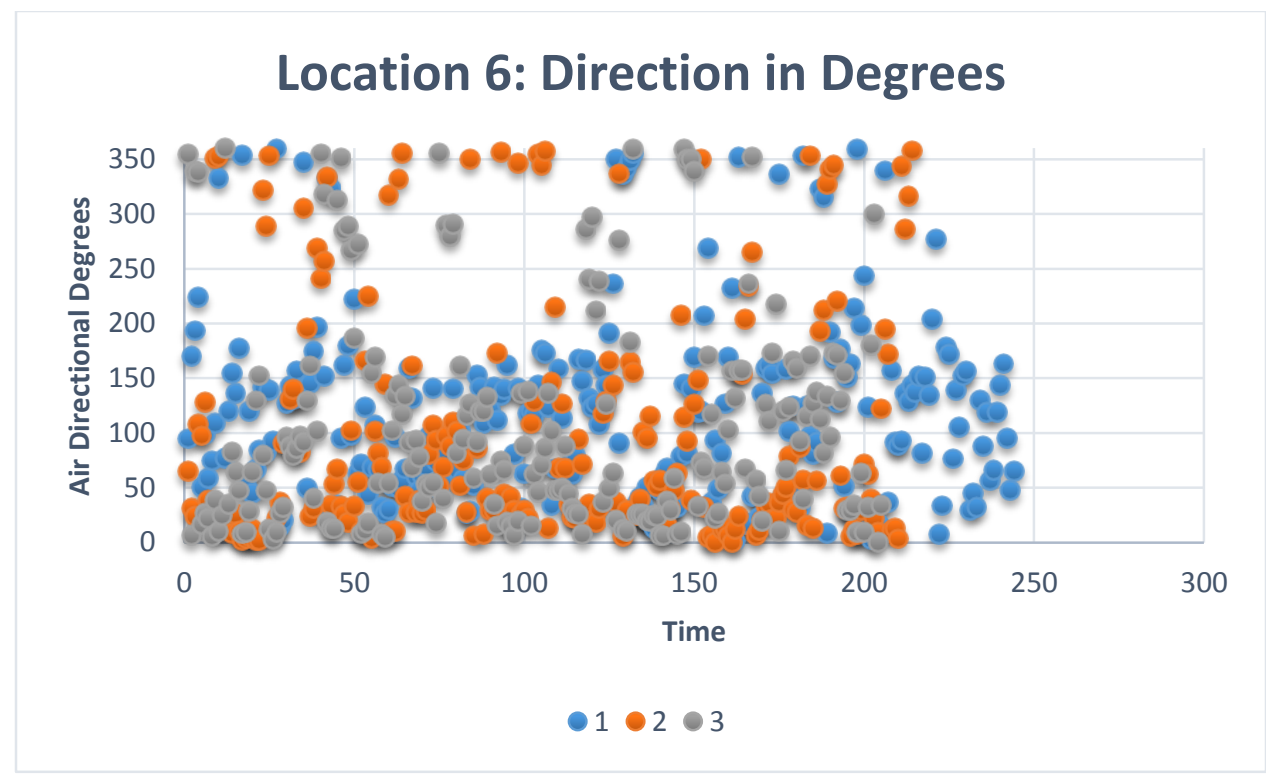

Appendix Figure 11: Graphical data of velocity direction in degrees over time for the three test repeats

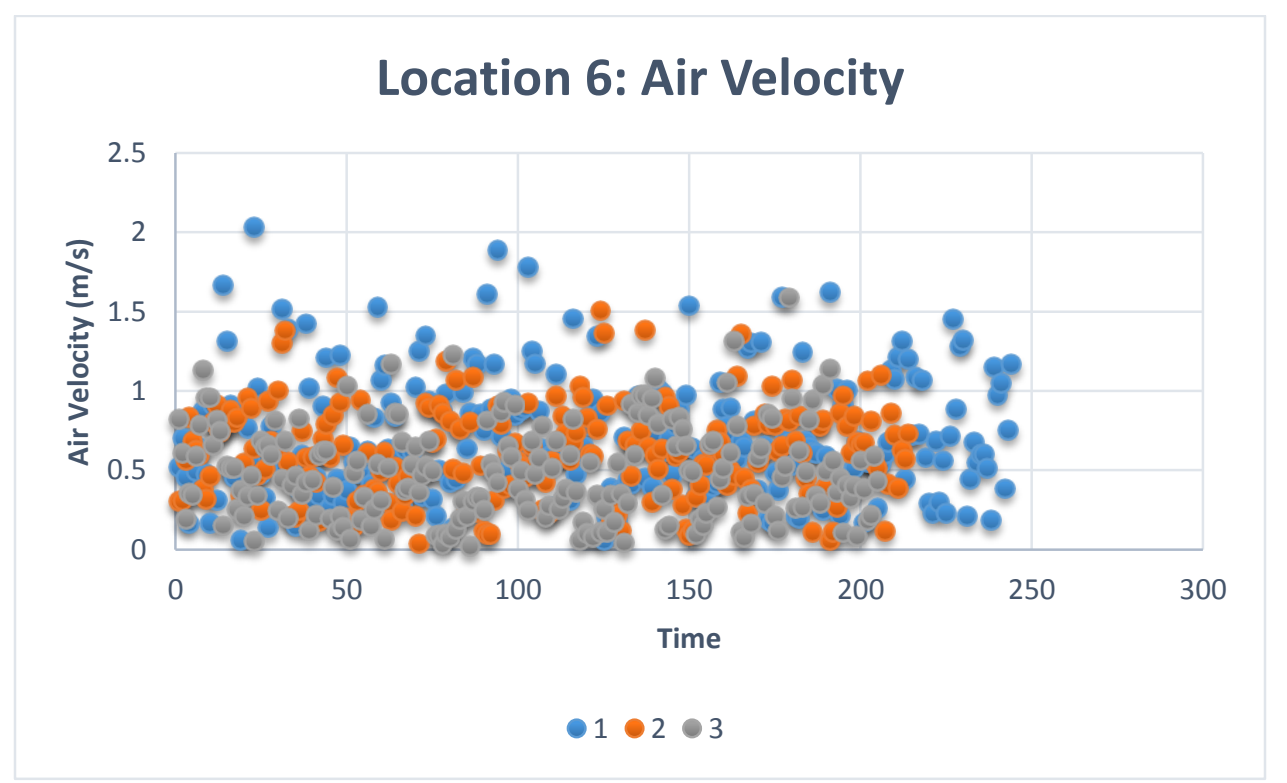

Appendix Figure 12: Graphical data of air velocity magnitude $(\mathrm{m} / \mathrm{s})$ over time for the three test repeats 


\begin{tabular}{|c|c|c|c|}
\hline \multicolumn{2}{|c|}{ Location 6 Air Velocity } & \multicolumn{2}{|c|}{ Location 6 Directional Degree } \\
\hline Mean & 0.610238 & Mean & 108.6295 \\
\hline Standard Error & 0.013172 & Standard Error & 3.758882 \\
\hline Median & 0.585154 & Median & 81.76592 \\
\hline Mode & 1.313202 & Mode & 29.99994 \\
\hline Standard Deviation & 0.339156 & Standard Deviation & 96.78664 \\
\hline Sample Variance & 0.115027 & Sample Variance & 9367.654 \\
\hline Kurtosis & 0.684678 & Kurtosis & 0.659812 \\
\hline Skewness & 0.735375 & Skewness & 1.213089 \\
\hline Range & 2.013615 & Range & 359.74 \\
\hline Minimum & 0.019756 & Minimum & 0.25513 \\
\hline Maximum & 2.033372 & Maximum & 359.9951 \\
\hline Sum & 404.5877 & Sum & 72021.38 \\
\hline Count & 663 & Count & 663 \\
\hline Confidence Level(95.0\%) & 0.025863 & Confidence Level(95.0\%) & 7.380767 \\
\hline
\end{tabular}




\begin{tabular}{|c|c|c|c|}
\hline \multicolumn{2}{|c|}{ Location 6 Velocity } & \multicolumn{2}{|c|}{ Location 6 Degree } \\
\hline Bin & Frequency & Bin & Frequency \\
\hline 0.019756 & 1 & 0.25513 & 1 \\
\hline 0.100301 & 20 & 14.64473 & 67 \\
\hline 0.180846 & 37 & 29.03433 & 73 \\
\hline 0.26139 & 51 & 43.42393 & 76 \\
\hline 0.341935 & 46 & 57.81353 & 48 \\
\hline 0.422479 & 55 & 72.20313 & 47 \\
\hline 0.503024 & 57 & 86.59272 & 29 \\
\hline 0.583569 & 64 & 100.9823 & 42 \\
\hline 0.664113 & 78 & 115.3719 & 23 \\
\hline 0.744658 & 45 & 129.7615 & 45 \\
\hline 0.825202 & 46 & 144.1511 & 38 \\
\hline 0.905747 & 44 & 158.5407 & 28 \\
\hline 0.986292 & 39 & 172.9303 & 29 \\
\hline 1.066836 & 17 & 187.3199 & 13 \\
\hline 1.147381 & 15 & 201.7095 & 8 \\
\hline 1.227925 & 13 & 216.0991 & 8 \\
\hline 1.30847 & 9 & 230.4887 & 5 \\
\hline 1.389015 & 10 & 244.8783 & 8 \\
\hline 1.469559 & 4 & 259.2679 & 1 \\
\hline 1.550104 & 4 & 273.6575 & 5 \\
\hline 1.630648 & 4 & 288.0471 & 6 \\
\hline 1.711193 & 1 & 302.4367 & 6 \\
\hline 1.791738 & 1 & 316.8263 & 4 \\
\hline 1.872282 & 0 & 331.2159 & 6 \\
\hline 1.952827 & 1 & 345.6055 & 16 \\
\hline More & 1 & More & 31 \\
\hline
\end{tabular}

Appendix Table 12: Histogram of location 6 air flow directional degrees and velocity $(\mathrm{m} / \mathrm{s})$

Location 7: (Blowing Curtain Location) 


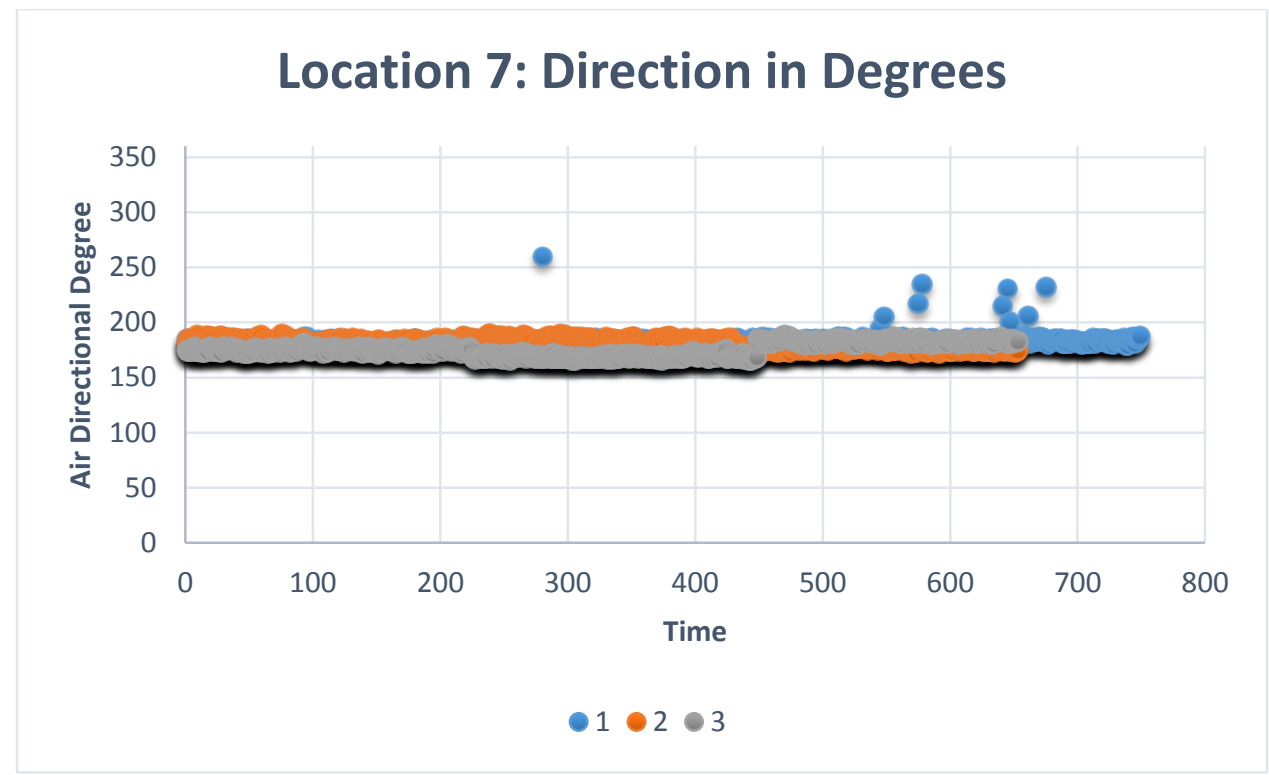

Appendix Figure 13: Graphical data of velocity direction in degrees over time for the three test repeats

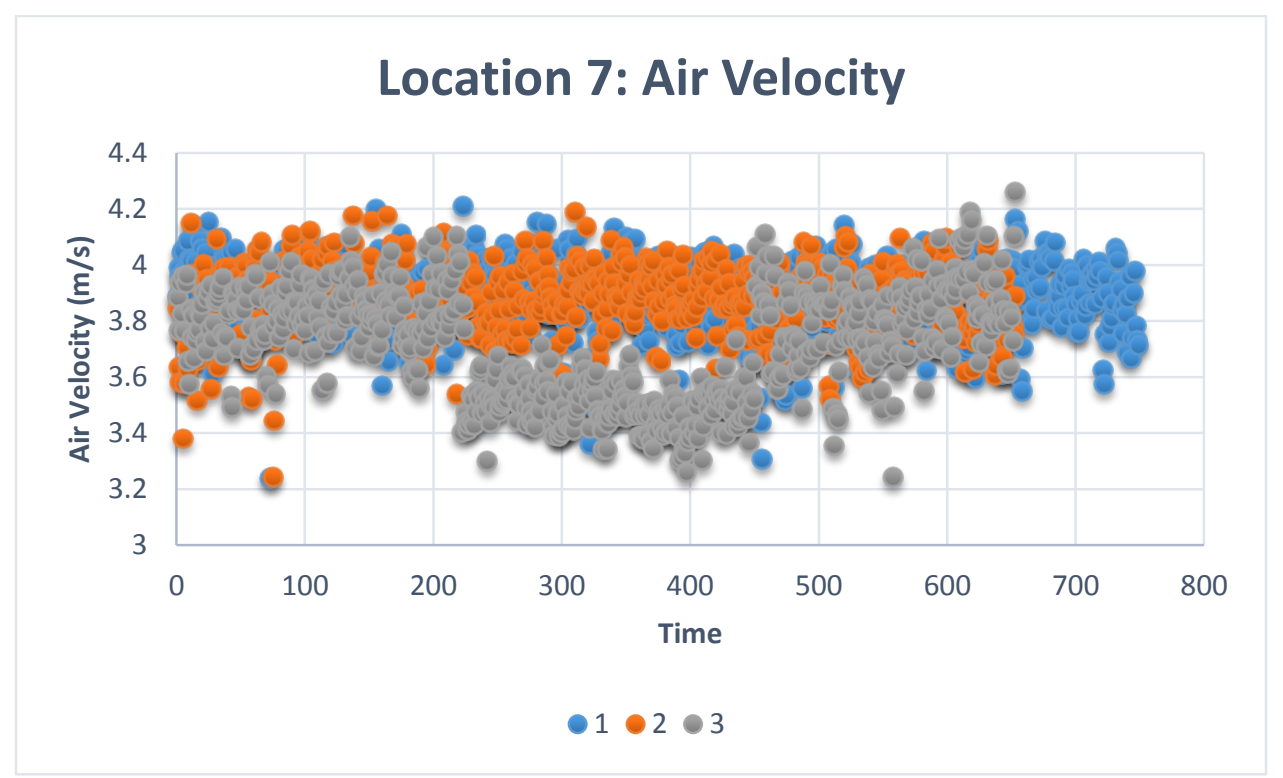

Appendix Figure 14: Graphical data of air velocity magnitude $(\mathrm{m} / \mathrm{s})$ over time for the three test repeats 


\begin{tabular}{lrrrrr}
\hline \multicolumn{2}{c}{ Location 7 Velocity } & & & & \multicolumn{2}{c}{ Location 7 Degrees } \\
\cline { 1 - 1 } Mean & & & & \\
Standard Error & 3.816984 & & Mean & 179.9377 \\
Median & 0.005092 & & Standard Error & 0.132789 \\
Mode & 3.858108 & & Median & 181.1822 \\
Standard Deviation & 3.850987 & & Mode & 182.1635 \\
Sample Variance & 0.230819 & & Standard Deviation & 6.019615 \\
Kurtosis & 0.053277 & & Sample Variance & 36.23577 \\
Skewness & 52.70936 & & Kurtosis & 23.98187 \\
Range & -5.03311 & & Skewness & 1.834123 \\
Minimum & 3.879026 & & Range & 94.1658 \\
Maximum & 0.382753 & & Minimum & 165.6896 \\
Sum & 4.261779 & & Maximum & 259.8554 \\
Count & 7843.901 & & Sum & 369771.9 \\
Confidence Level(95.0\%) & 2055 & & Count & 2055 \\
\cline { 1 - 2 } Appendix Table & 0.009986 & & Confidence Level(95.0\%) & 0.260416 \\
\hline
\end{tabular}

Appendix Table 13: Statistical breakdown of location 7 air flow directional degrees and velocity 


\begin{tabular}{|c|c|c|c|}
\hline \multicolumn{2}{|c|}{ Location 7 Velocity } & \multicolumn{2}{|c|}{ Locaiton 7 Degrees } \\
\hline Bin & Frequency & Bin & Frequency \\
\hline 0.382753 & 1 & 165.6896 & 1 \\
\hline 0.468954 & 0 & 167.7822 & 24 \\
\hline 0.555154 & 0 & 169.8747 & 136 \\
\hline 0.641355 & 0 & 171.9673 & 57 \\
\hline 0.727555 & 0 & 174.0599 & 97 \\
\hline 0.813756 & 0 & 176.1525 & 176 \\
\hline 0.899957 & 0 & 178.245 & 161 \\
\hline 0.986157 & 0 & 180.3376 & 202 \\
\hline 1.072358 & 0 & 182.4302 & 501 \\
\hline 1.158558 & 1 & 184.5228 & 334 \\
\hline 1.244759 & 1 & 186.6153 & 294 \\
\hline 1.33096 & 0 & 188.7079 & 54 \\
\hline 1.41716 & 0 & 190.8005 & 8 \\
\hline 1.503361 & 0 & 192.8931 & 0 \\
\hline 1.589561 & 0 & 194.9856 & 1 \\
\hline 1.675762 & 0 & 197.0782 & 0 \\
\hline 1.761962 & 1 & 199.1708 & 0 \\
\hline 1.848163 & 0 & 201.2633 & 1 \\
\hline 1.934364 & 1 & 203.3559 & 0 \\
\hline 2.020564 & 2 & 205.4485 & 1 \\
\hline 2.106765 & 0 & 207.5411 & 1 \\
\hline 2.192965 & 1 & 209.6336 & 0 \\
\hline 2.279166 & 1 & 211.7262 & 0 \\
\hline 2.365367 & 0 & 213.8188 & 0 \\
\hline 2.451567 & 1 & 215.9114 & 1 \\
\hline 2.537768 & 0 & 218.0039 & 1 \\
\hline 2.623968 & 0 & 220.0965 & 0 \\
\hline 2.710169 & 0 & 222.1891 & 0 \\
\hline 2.796369 & 1 & 224.2817 & 0 \\
\hline 2.88257 & 0 & 226.3742 & 0 \\
\hline 2.968771 & 0 & 228.4668 & 0 \\
\hline 3.054971 & 0 & 230.5594 & 0 \\
\hline 3.141172 & 0 & 232.6519 & 2 \\
\hline 3.227372 & 0 & 234.7445 & 1 \\
\hline 3.313573 & 8 & 236.8371 & 0 \\
\hline 3.399774 & 24 & 238.9297 & 0 \\
\hline 3.485974 & 84 & 241.0222 & 0 \\
\hline 3.572175 & 111 & 243.1148 & 0 \\
\hline 3.658375 & 105 & 245.2074 & 0 \\
\hline 3.744576 & 186 & 247.3 & 0 \\
\hline 3.830776 & 325 & 249.3925 & 0 \\
\hline 3.916977 & 512 & 251.4851 & 0 \\
\hline 4.003178 & 437 & 253.5777 & 0 \\
\hline 4.089378 & 207 & 255.6703 & 0 \\
\hline 4.175579 & 38 & 257.7628 & 0 \\
\hline More & 7 & More & 1 \\
\hline
\end{tabular}


Appendix Table 14: Histogram of location 7 air flow directional degrees and velocity $(\mathrm{m} / \mathrm{s})$

Location 8:

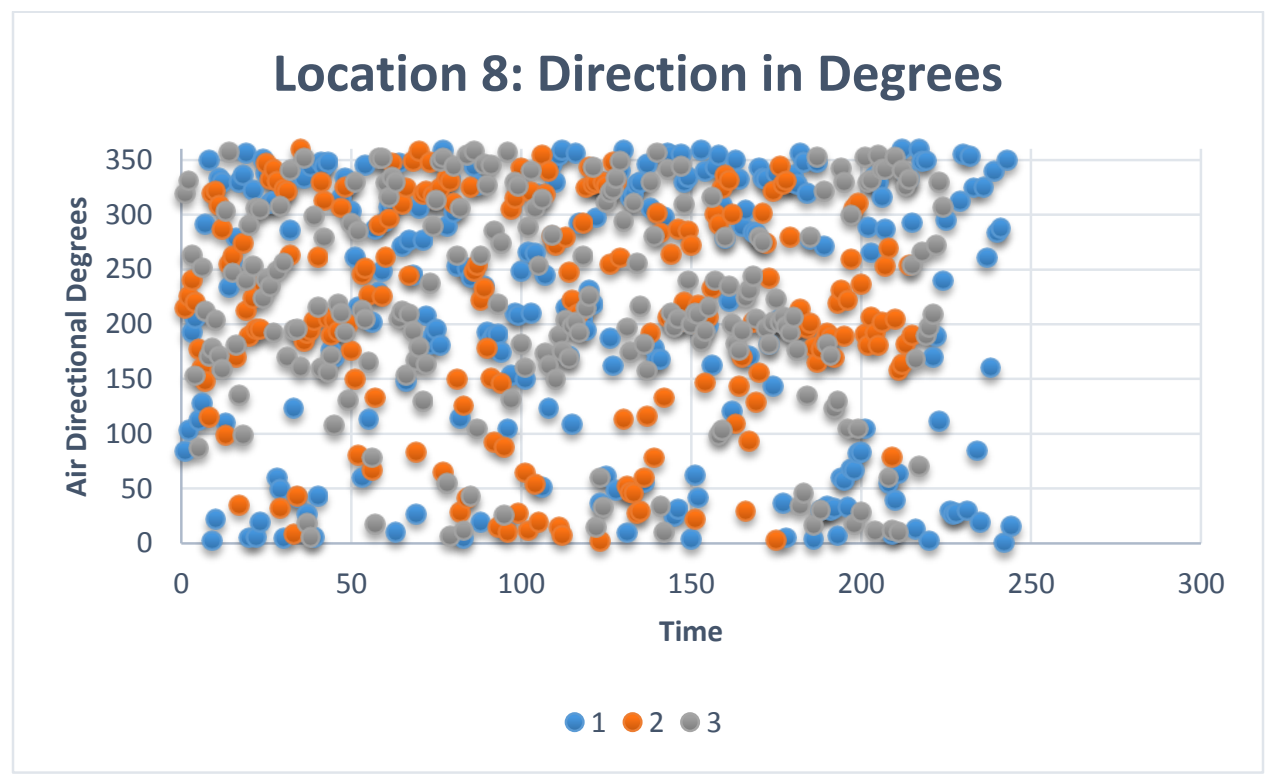

Appendix Figure 15: Graphical data of velocity direction in degrees over time for the three test repeats

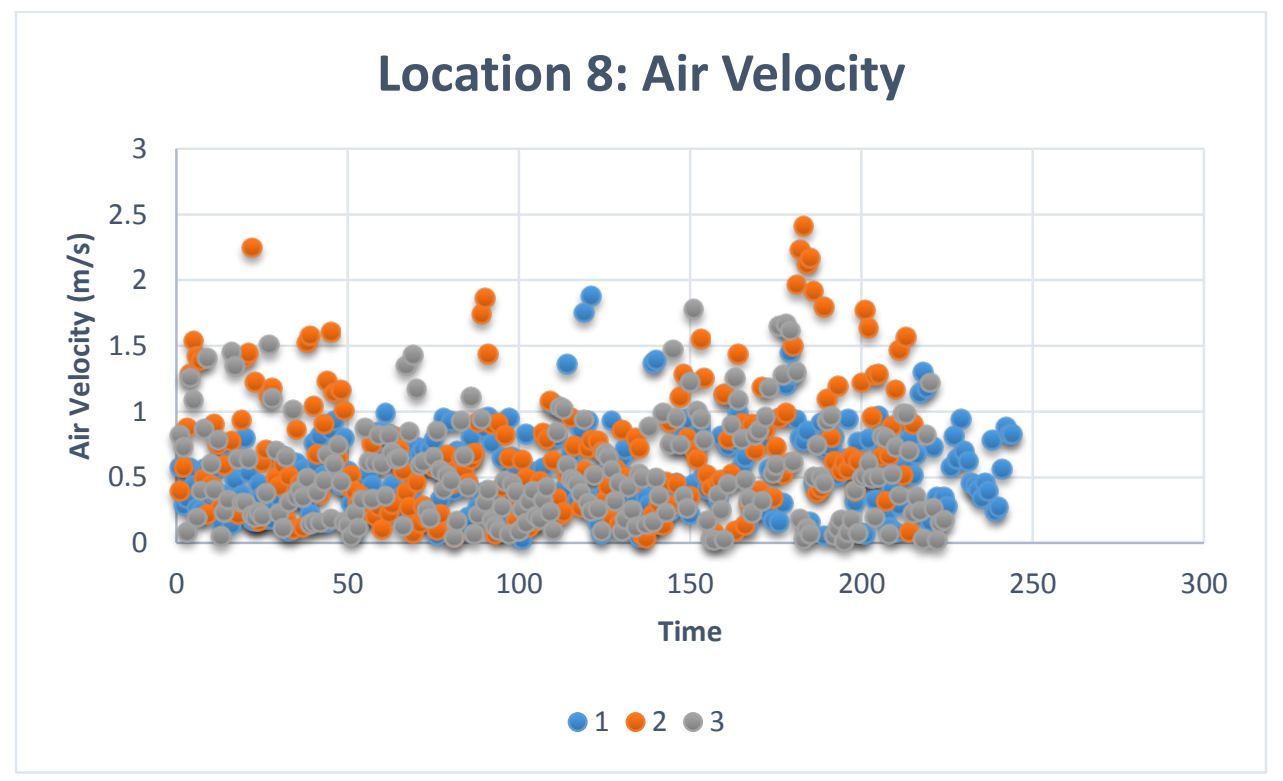

Appendix Figure 16: Graphical data of air velocity magnitude $(\mathrm{m} / \mathrm{s})$ over time for the three test repeats 


\begin{tabular}{|c|c|c|c|}
\hline \multicolumn{2}{|c|}{ Location 8 Velocity } & \multicolumn{2}{|c|}{ Location 8 Degree } \\
\hline Mean & 0.592371 & Mean & 216.0503 \\
\hline Standard Error & 0.015644 & Standard Error & 4.071941 \\
\hline Median & 0.513128 & Median & 220.0172 \\
\hline Mode & 0.170294 & Mode & 330.0001 \\
\hline Standard Deviation & 0.408853 & Standard Deviation & 106.4172 \\
\hline Sample Variance & 0.167161 & Sample Variance & 11324.62 \\
\hline Kurtosis & 1.856655 & Kurtosis & -0.85355 \\
\hline Skewness & 1.219458 & Skewness & -0.50633 \\
\hline Range & 2.394098 & Range & 359.3015 \\
\hline Minimum & 0.018204 & Minimum & 0.629969 \\
\hline Maximum & 2.412302 & Maximum & 359.9315 \\
\hline Sum & 404.5893 & Sum & 147562.4 \\
\hline Count & 683 & Count & 683 \\
\hline Confidence Level(95.0\%) & 0.030717 & Confidence Level(95.0\%) & 7.995046 \\
\hline
\end{tabular}




\begin{tabular}{|c|c|c|c|}
\hline \multicolumn{2}{|c|}{ Location 8: Velocity } & \multicolumn{2}{|c|}{ Location 8: Degree } \\
\hline Bin & Frequency & Bin & Frequency \\
\hline 0.018204 & 1 & 0.629969 & 1 \\
\hline 0.110284 & 44 & 14.44926 & 28 \\
\hline 0.202365 & 64 & 28.26855 & 23 \\
\hline 0.294446 & 63 & 42.08784 & 23 \\
\hline 0.386527 & 74 & 55.90713 & 15 \\
\hline 0.478607 & 73 & 69.72642 & 15 \\
\hline 0.570688 & 63 & 83.5457 & 8 \\
\hline 0.662769 & 60 & 97.36499 & 6 \\
\hline 0.754849 & 45 & 111.1843 & 14 \\
\hline 0.84693 & 48 & 125.0036 & 11 \\
\hline 0.939011 & 38 & 138.8229 & 11 \\
\hline 1.031092 & 27 & 152.6422 & 11 \\
\hline 1.123172 & 10 & 166.4614 & 20 \\
\hline 1.215253 & 14 & 180.2807 & 32 \\
\hline 1.307334 & 16 & 194.1 & 43 \\
\hline 1.399414 & 6 & 207.9193 & 50 \\
\hline 1.491495 & 11 & 221.7386 & 32 \\
\hline 1.583576 & 7 & 235.5579 & 21 \\
\hline 1.675657 & 5 & 249.3772 & 22 \\
\hline 1.767737 & 2 & 263.1965 & 26 \\
\hline 1.859818 & 3 & 277.0158 & 17 \\
\hline 1.951899 & 3 & 290.835 & 32 \\
\hline 2.043979 & 1 & 304.6543 & 23 \\
\hline 2.13606 & 1 & 318.4736 & 36 \\
\hline 2.228141 & 1 & 332.2929 & 64 \\
\hline 2.320222 & 2 & 346.1122 & 46 \\
\hline More & 1 & More & 53 \\
\hline
\end{tabular}

Appendix Table 16: Histogram of location 8 air flow directional degrees and velocity $(\mathrm{m} / \mathrm{s})$

Location 9: 


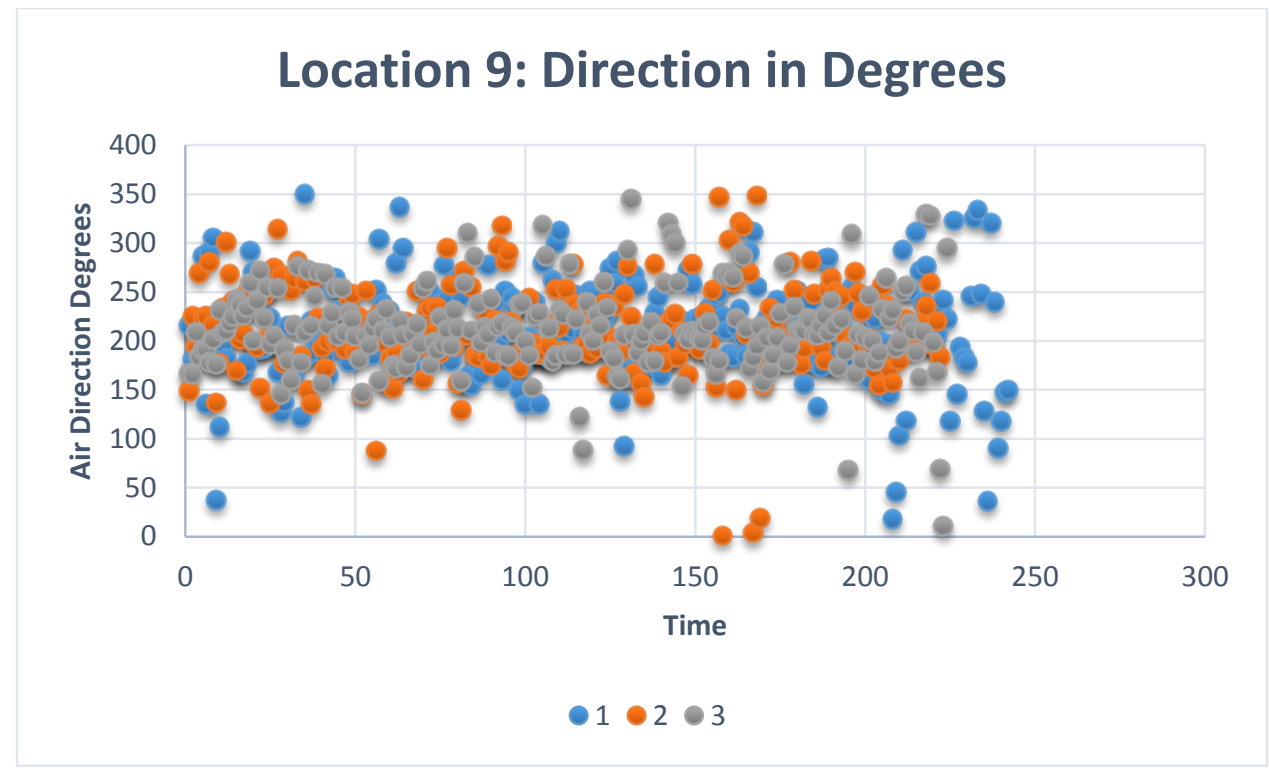

Appendix Figure 17: Graphical data of velocity direction in degrees over time for the three test repeats

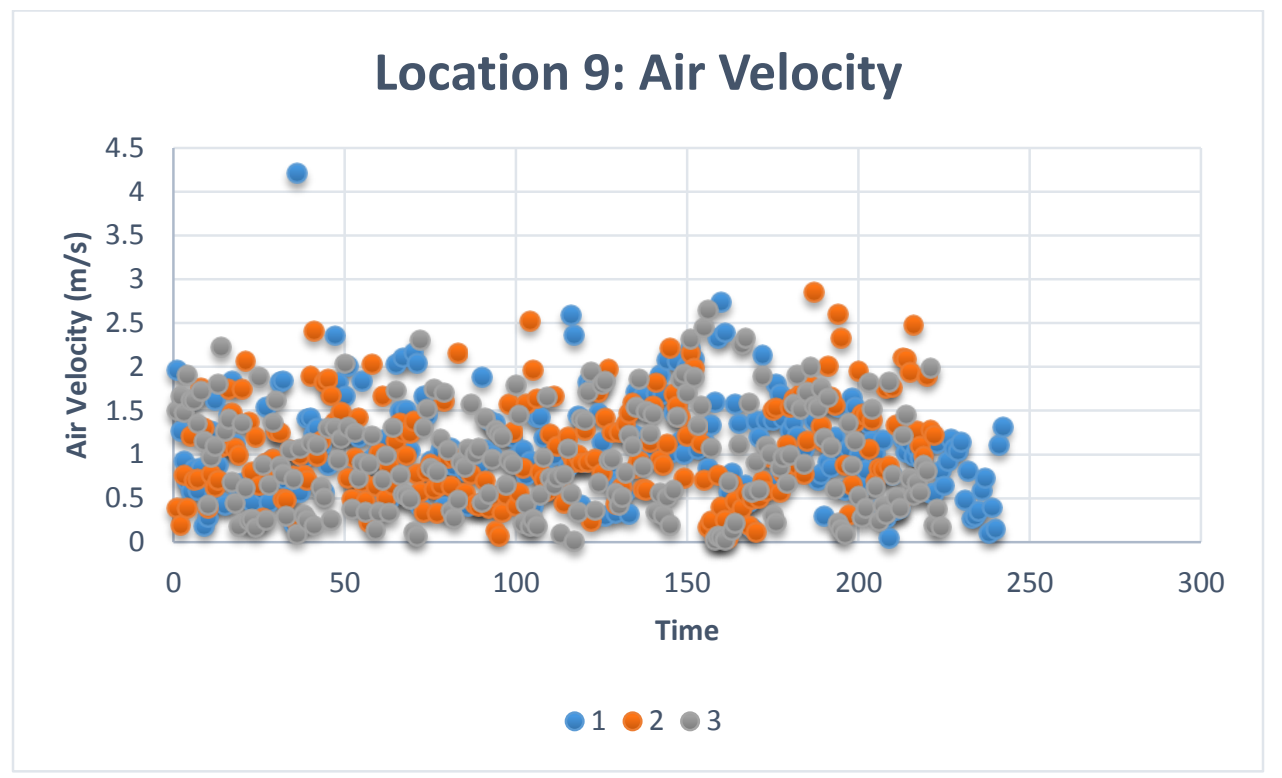

Appendix Figure 18: Graphical data of air velocity magnitude $(\mathrm{m} / \mathrm{s})$ over time for the three test repeats 


\begin{tabular}{|c|c|c|c|}
\hline \multicolumn{2}{|c|}{ Location 9 Air Velocity } & \multicolumn{2}{|c|}{ Location 9 Directional Degree } \\
\hline Mean & 1.037884 & Mean & 211.5215 \\
\hline Standard Error & 0.022055 & Standard Error & 1.839078 \\
\hline Median & 0.97811 & Median & 207.5005 \\
\hline Mode & 0.572713 & Mode & 178.5347 \\
\hline Standard Deviation & 0.578505 & Standard Deviation & 48.23857 \\
\hline Sample Variance & 0.334668 & Sample Variance & 2326.96 \\
\hline Kurtosis & 0.788893 & Kurtosis & 2.471597 \\
\hline Skewness & 0.655464 & Skewness & -0.38433 \\
\hline Range & 4.199915 & Range & 349.261 \\
\hline Minimum & 0.011795 & Minimum & 0.963992 \\
\hline Maximum & 4.21171 & Maximum & 350.225 \\
\hline Sum & 714.0642 & Sum & 145526.8 \\
\hline Count & 688 & Count & 688 \\
\hline Confidence Level(95.0\%) & 0.043304 & Confidence Level(95.0\%) & 3.610889 \\
\hline
\end{tabular}

Appendix Table 17: Statistical breakdown of location 9 air flow directional degrees and velocity 


\begin{tabular}{|c|c|c|c|}
\hline \multicolumn{2}{|c|}{ Location 9 Velocity } & \multicolumn{2}{|c|}{ Locaiton 9 Degree } \\
\hline Bin & Frequency & Bin & Frequency \\
\hline 0.011795 & 1 & 0.963992 & 1 \\
\hline 0.17333 & 23 & 14.39711 & 2 \\
\hline 0.334865 & 46 & 27.83022 & 2 \\
\hline 0.496401 & 60 & 41.26333 & 2 \\
\hline 0.657936 & 75 & 54.69645 & 1 \\
\hline 0.819471 & 65 & 68.12956 & 0 \\
\hline 0.981006 & 75 & 81.56268 & 2 \\
\hline 1.142541 & 74 & 94.99579 & 4 \\
\hline 1.304076 & 62 & 108.4289 & 1 \\
\hline 1.465612 & 51 & 121.862 & 4 \\
\hline 1.627147 & 39 & 135.2951 & 6 \\
\hline 1.788682 & 38 & 148.7282 & 16 \\
\hline 1.950217 & 33 & 162.1614 & 28 \\
\hline 2.111752 & 20 & 175.5945 & 36 \\
\hline 2.273287 & 8 & 189.0276 & 93 \\
\hline 2.434823 & 9 & 202.4607 & 106 \\
\hline 2.596358 & 3 & 215.8938 & 96 \\
\hline 2.757893 & 4 & 229.3269 & 77 \\
\hline 2.919428 & 1 & 242.76 & 54 \\
\hline 3.080963 & 0 & 256.1932 & 49 \\
\hline 3.242498 & 0 & 269.6263 & 33 \\
\hline 3.404034 & 0 & 283.0594 & 29 \\
\hline 3.565569 & 0 & 296.4925 & 16 \\
\hline 3.727104 & 0 & 309.9256 & 9 \\
\hline 3.888639 & 0 & 323.3587 & 12 \\
\hline 4.050174 & 0 & 336.7918 & 4 \\
\hline More & 1 & More & 5 \\
\hline
\end{tabular}

Appendix Table 18: Histogram of location 9 air flow directional degrees and velocity $(\mathrm{m} / \mathrm{s})$

Location 10: 


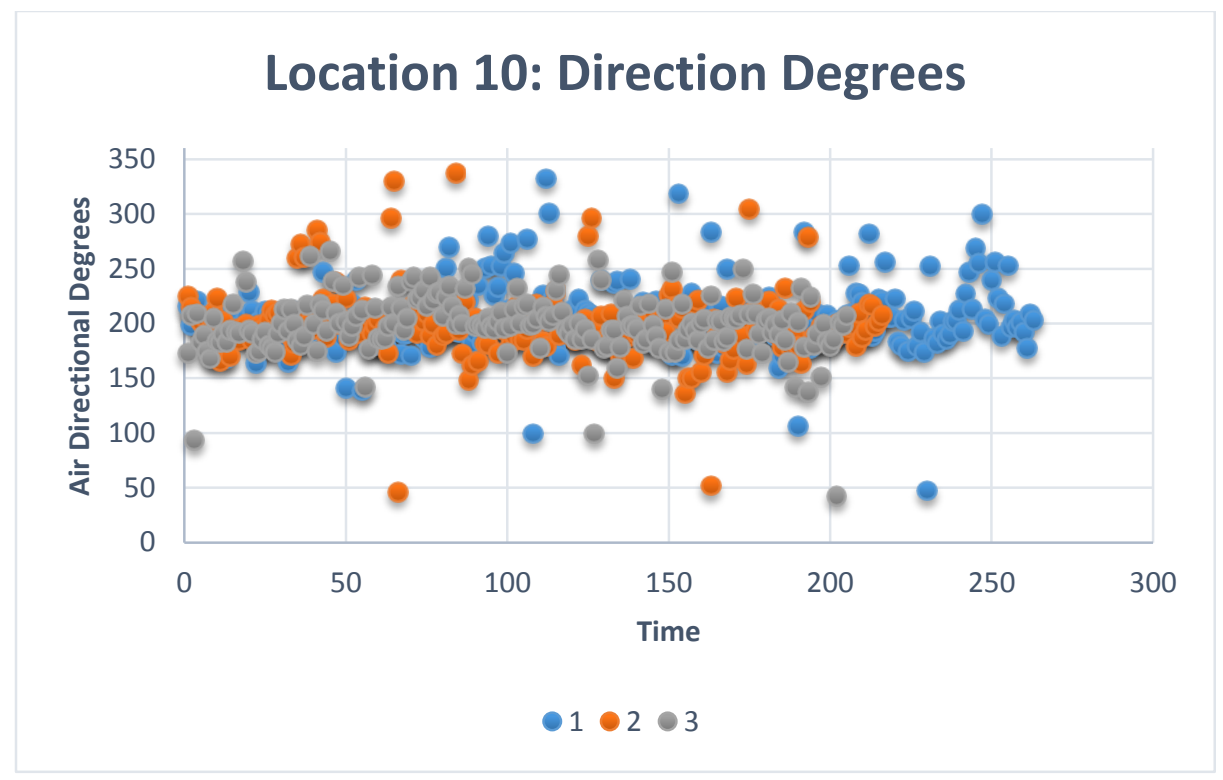

Appendix Figure 19: Graphical data of velocity direction in degrees over time for the three test repeats

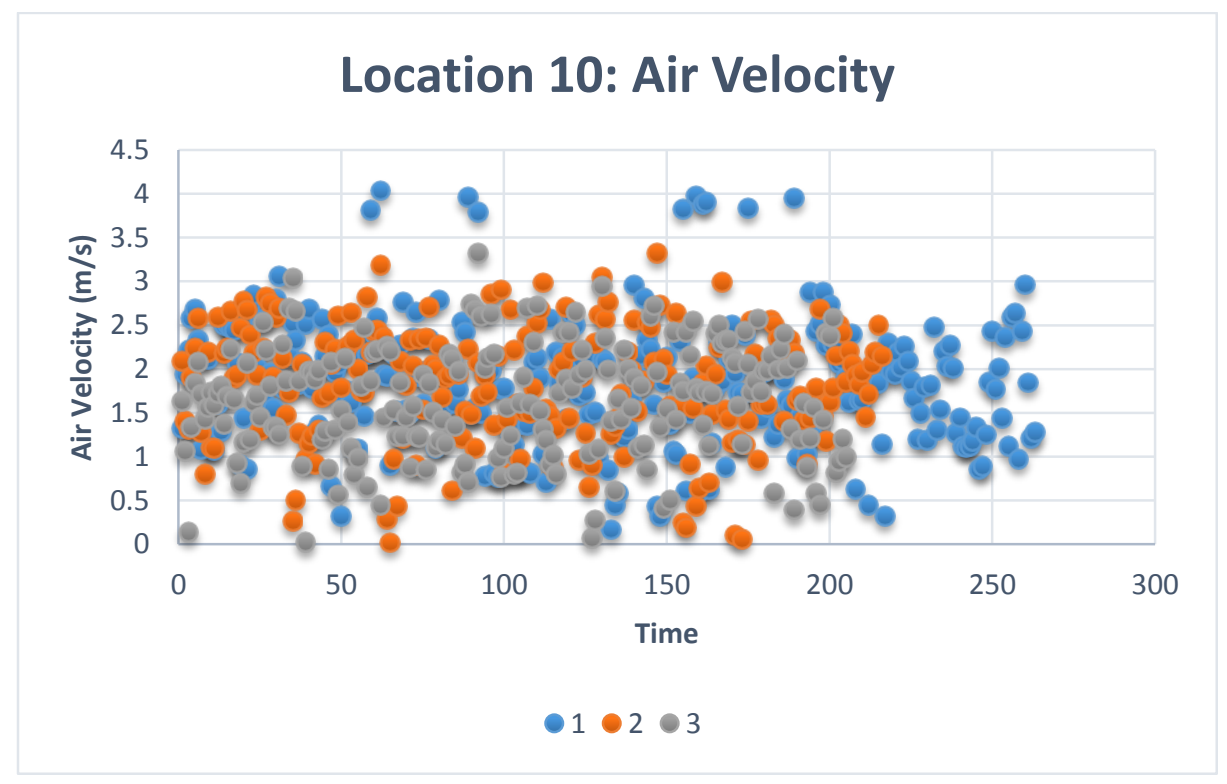

Appendix Figure 20: Graphical data of air velocity magnitude $(\mathrm{m} / \mathrm{s})$ over time for the three test repeats 


\begin{tabular}{|c|c|c|c|}
\hline \multicolumn{2}{|c|}{ Location 10 Velocity } & \multicolumn{2}{|c|}{ Location 10 Degree } \\
\hline Mean & 1.777256 & Mean & 201.4132 \\
\hline Standard Error & 0.026172 & Standard Error & 1.146698 \\
\hline Median & 1.809495 & Median & 199.2518 \\
\hline Mode & 1.597028 & Mode & 220.9981 \\
\hline Standard Deviation & 0.684496 & Standard Deviation & 29.99004 \\
\hline Sample Variance & 0.468534 & Sample Variance & 899.4025 \\
\hline Kurtosis & 0.385845 & Kurtosis & 6.516893 \\
\hline Skewness & 0.097763 & Skewness & 0.047269 \\
\hline Range & 4.020791 & Range & 295.0763 \\
\hline Minimum & 0.02 & Minimum & 42.39526 \\
\hline Maximum & 4.040792 & Maximum & 337.4716 \\
\hline Sum & 1215.643 & Sum & 137766.6 \\
\hline Count & 684 & Count & 684 \\
\hline Confidence Level(95.0\%) & 0.051388 & Confidence Level(95.0\%) & 2.251476 \\
\hline
\end{tabular}




\begin{tabular}{|c|c|c|c|}
\hline \multicolumn{2}{|c|}{ Location 10 Velocity } & \multicolumn{2}{|c|}{ Location 10 Degree } \\
\hline Bin & Frequency & Bin & Frequency \\
\hline 0.02 & 1 & 42.39526 & 1 \\
\hline 0.174646 & 6 & 53.74435 & 3 \\
\hline 0.329292 & 8 & 65.09344 & 0 \\
\hline 0.483938 & 9 & 76.44253 & 0 \\
\hline 0.638584 & 12 & 87.79162 & 0 \\
\hline 0.79323 & 11 & 99.14071 & 1 \\
\hline 0.947875 & 35 & 110.4898 & 3 \\
\hline 1.102521 & 30 & 121.8389 & 0 \\
\hline 1.257167 & 46 & 133.188 & 0 \\
\hline 1.411813 & 41 & 144.5371 & 7 \\
\hline 1.566459 & 58 & 155.8862 & 7 \\
\hline 1.721104 & 48 & 167.2352 & 13 \\
\hline 1.87575 & 60 & 178.5843 & 50 \\
\hline 2.030396 & 67 & 189.9334 & 121 \\
\hline 2.185042 & 63 & 201.2825 & 169 \\
\hline 2.339688 & 55 & 212.6316 & 141 \\
\hline 2.494333 & 36 & 223.9807 & 76 \\
\hline 2.648979 & 42 & 235.3298 & 28 \\
\hline 2.803625 & 27 & 246.6789 & 19 \\
\hline 2.958271 & 10 & 258.028 & 17 \\
\hline 3.112917 & 6 & 269.3771 & 7 \\
\hline 3.267563 & 1 & 280.7261 & 8 \\
\hline 3.422208 & 2 & 292.0752 & 4 \\
\hline 3.576854 & 0 & 303.4243 & 4 \\
\hline 3.7315 & 0 & 314.7734 & 1 \\
\hline 3.886146 & 5 & 326.1225 & 1 \\
\hline More & 5 & More & 3 \\
\hline
\end{tabular}

Appendix Table 20: Histogram of location 10 air flow directional degrees and velocity $(\mathrm{m} / \mathrm{s})$ 